هشام عثمان عبد الرحمن وآخربن - إجراءات صبانة مبانى التعليم "المعلكة المتحدة وجههورية مصر العربية -

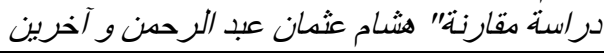

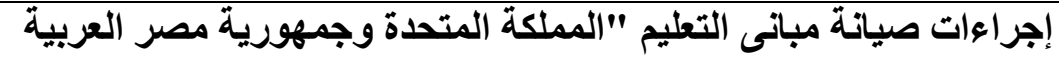 - دراسة مقارنة " \\ د. نادى مصطقى عبد الكريم 3 م. هشام عثمان عبد الرحمن 1، " أ.د. محمد عبد السميع عيد 2

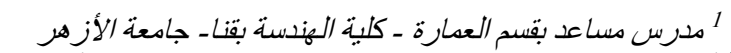 2، 3 أعضاء هيئة تدريب بقسم العندسة المعدارية بكلبة - جامعة أسيوط.
}

تاريخ الورود 22 يوليو 2012 ، تاريخ القبول 14 نوفمبر 2012

\section{ملخص البحث}

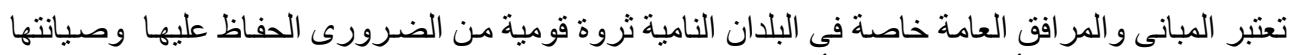

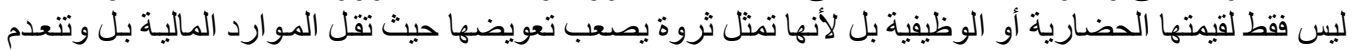

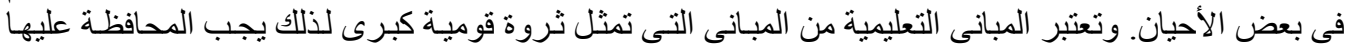

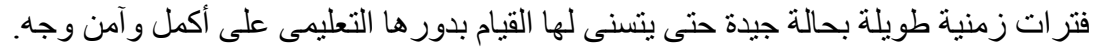

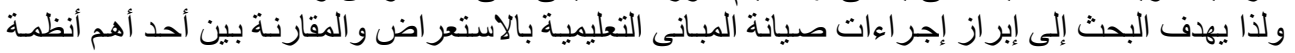

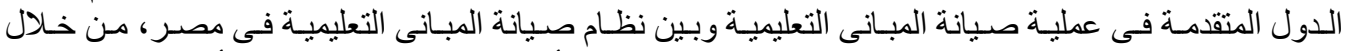

استعر اض تشريعات و إدارة ومر احل صيانة مبانى التعليم، وتحديد أوجه التشابه و الاختلاف فى أداء التهاء النظامين .

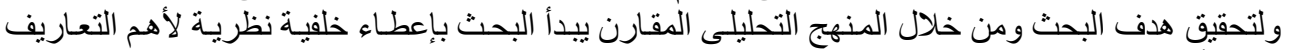

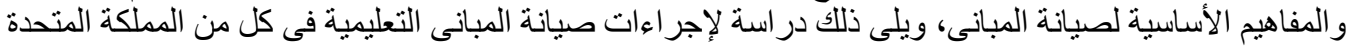

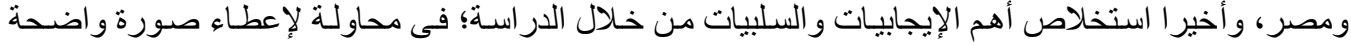

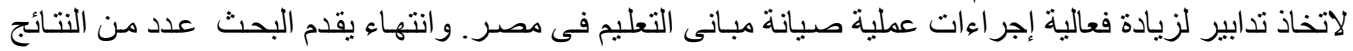

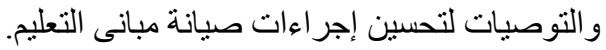
الكلمات المفتاحية: صيانة - مبانى التعليم- المملكة المتحدة - مصر .

\section{1}

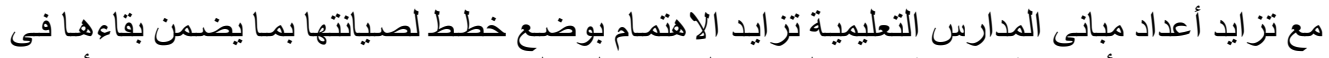

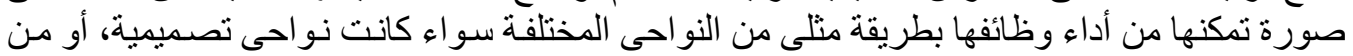

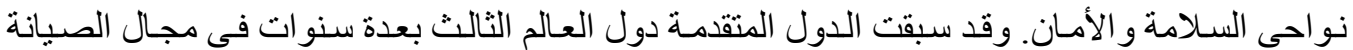

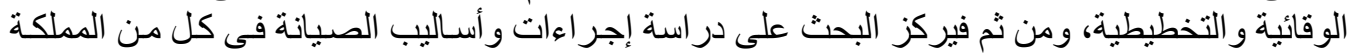

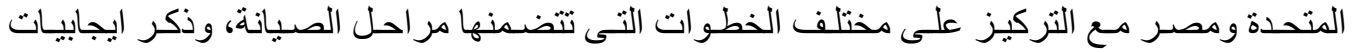

وسلبيات كل منها.

$$
1.1
$$

يهدف البحث إلى وصف وتحليل ومقارنة إجر اءات عملية صيانة المبانى التعليميـة في المملكة المتحدة

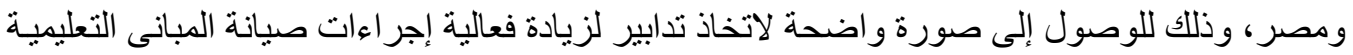


هشام عثمان عبد الرحمن وآخربن - إجراءات صبيانة مبانى التعليم "المدلكة الهتحدة وجمهورية مصر العربية

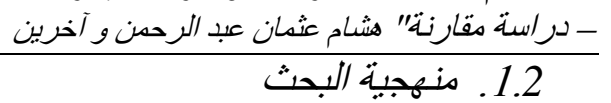

يعتمد البحث بشكل أساسـى على المنهج الوصفى التحليلى المقارن للمعلومـات التى يتم الحصـول

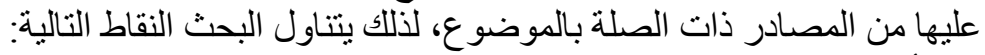
أـ صيانة المبانى (خلفية نظرية).

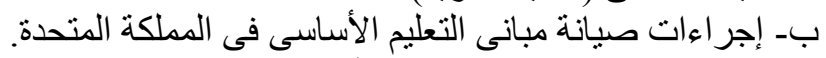

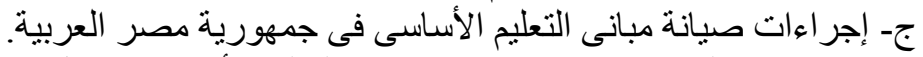
دـ ايجابيات وسلبيات إجر اءات صبيانة مبانى التعليم الأساسى في كلى كل من مصر و والمملكة المتحدة.

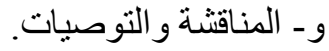

\section{2. صيانة المبانى (خلفية نظرية)}

على الر غم من أهمية وخطورة عملية الصيانة ودور ها فى الحفاظ على استثمار ات المبانى إلا أنها لم

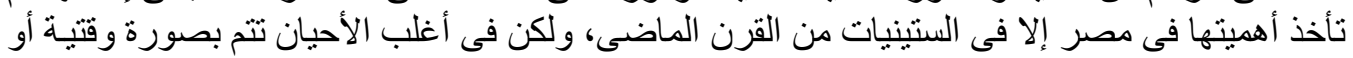

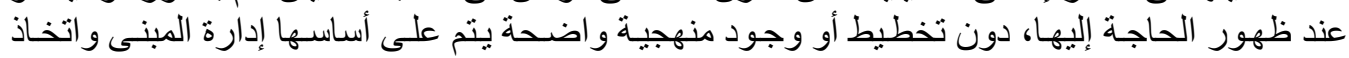

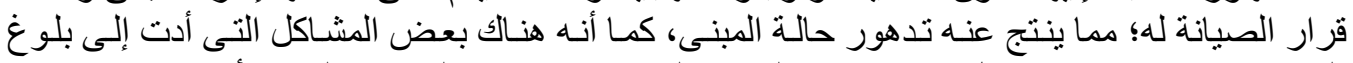

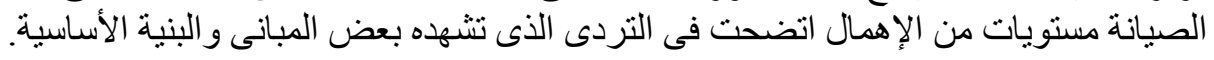

$$
\text { 2.1.1. مفهوم الصيانة الصبانة فحى اللغة }
$$

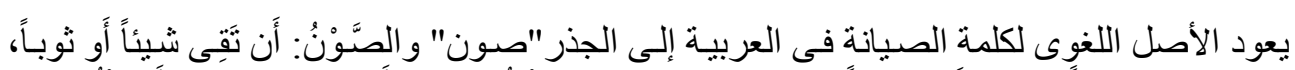

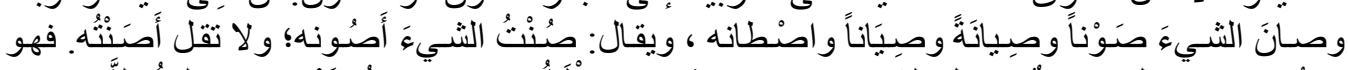

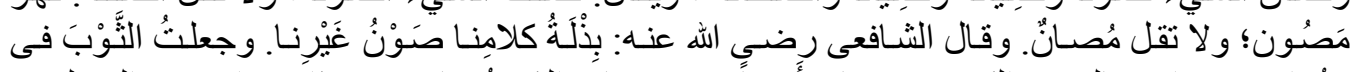

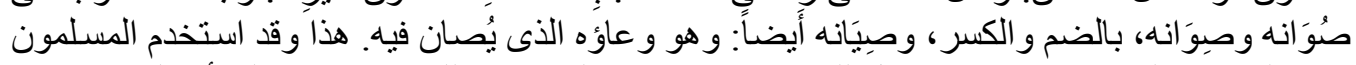

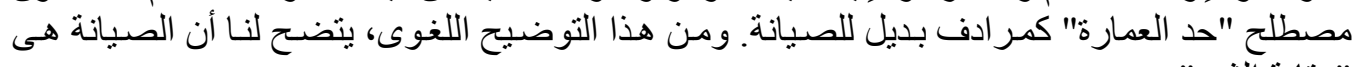

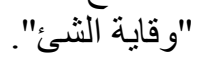

"Maintenance" 2.1.2 المفهوم العلمى للصيانة

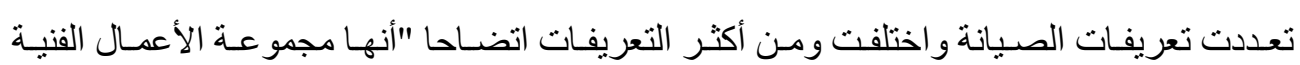

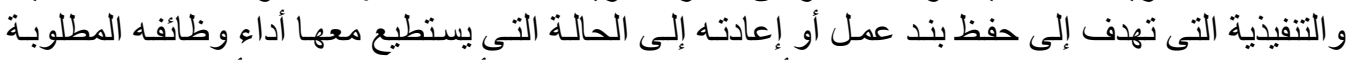

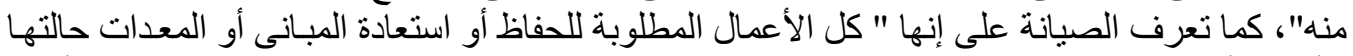

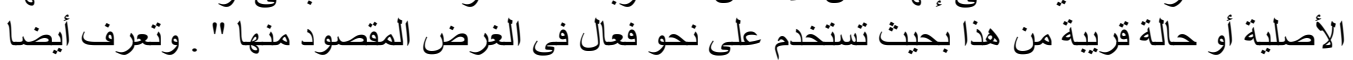

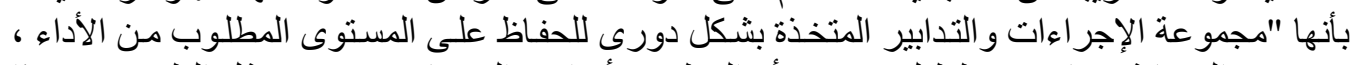

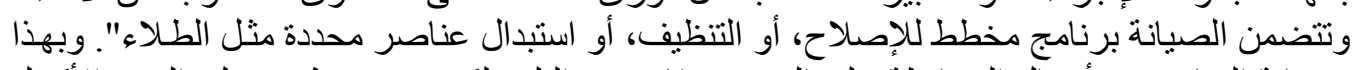

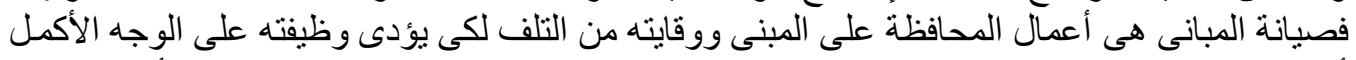

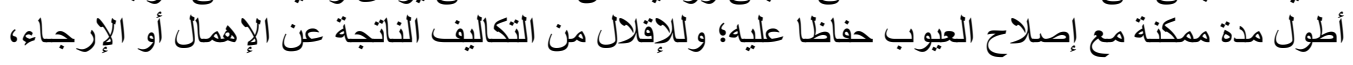

Journal of Engineering Sciences, Assiut University, Faculty of Engineering, Vol. 41, No. 2, pp. 617 -644, March, 2013,E-mail address: jes@aun.edu.eg 
هشام عثمان عبد الرحمن وآخربن - إجراءات صبيانة مبانى التعليم "المدلكة الهتحدة وجمهورية مصر العربية

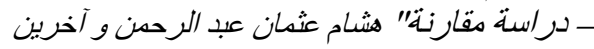

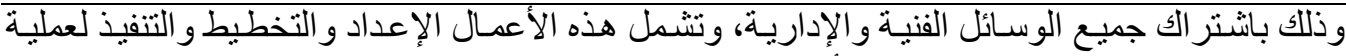

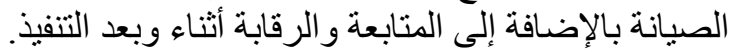

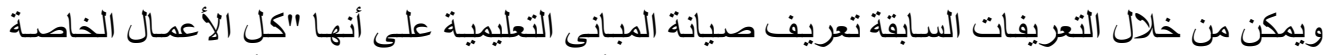

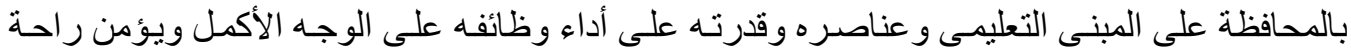
مستخدمبه".

\section{2. فلسفة الصبانتة}

إن فلسفة الصيانة للمبانى تبنى أساسا على عدم القدرة على إنتاج مبـان لا تحتاج إلى أعمال صيانة

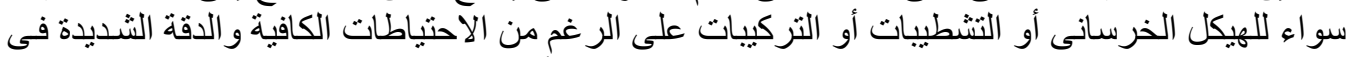

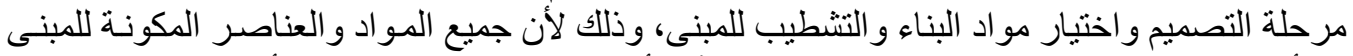

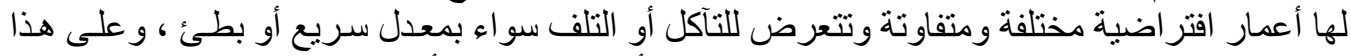

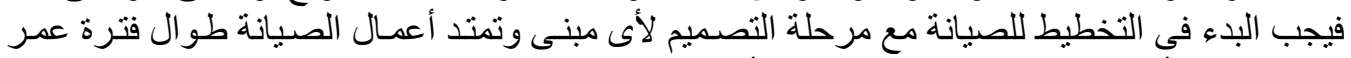

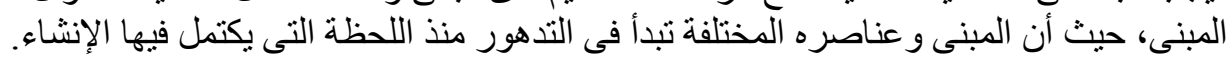

$$
\text { 2.3 }
$$

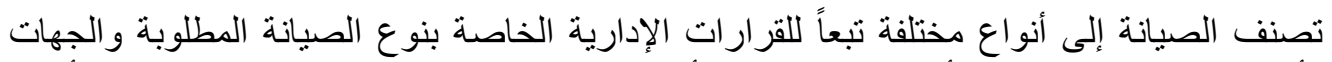

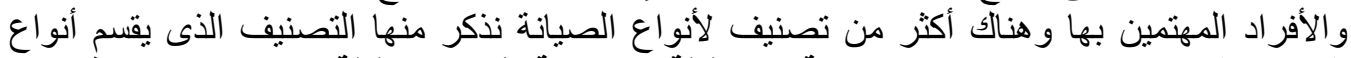

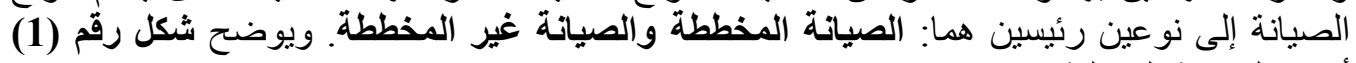
أنو اع الصيانة المختلفة ألو

\section{Planned maintenance 2.3.1 الصبانة المخططة}

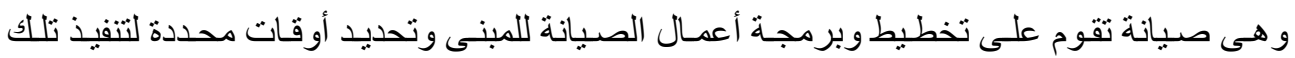

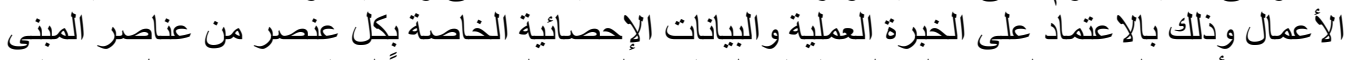

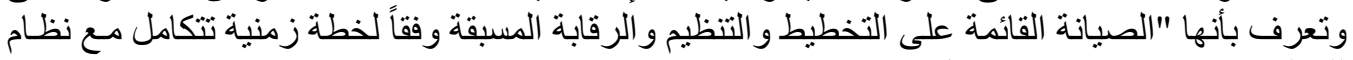

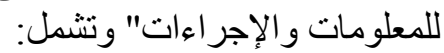

أ- الصبيانة الوقائية Preventive Maintenance

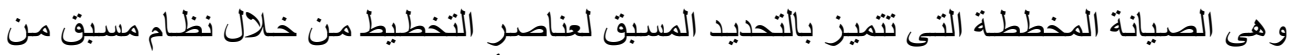

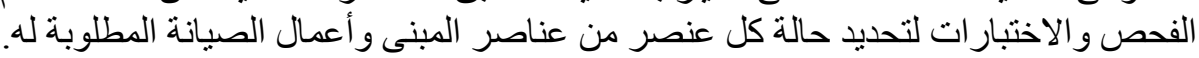

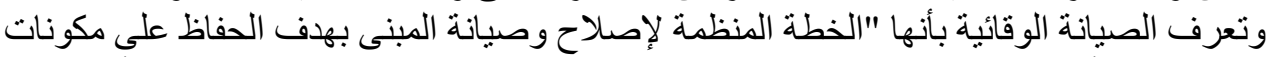

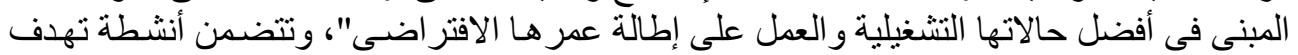

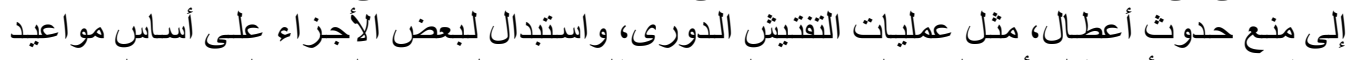

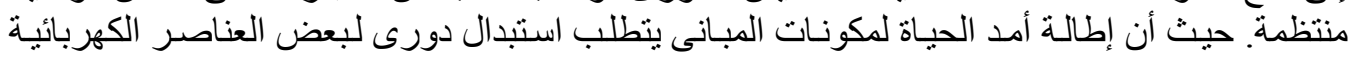

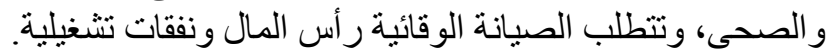
بـ بـ الصيانة التنبؤية ولنية

Journal of Engineering Sciences, Assiut University, Faculty of Engineering, Vol. 41, No. 2, pp. 617 -644, March,2013,E-mail address: jes@aun.edu.eg 


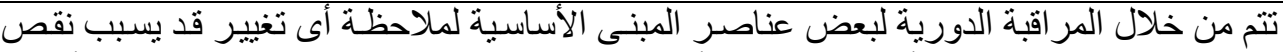

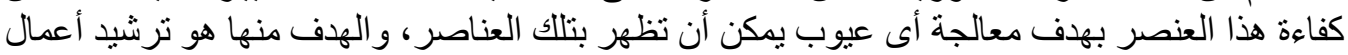

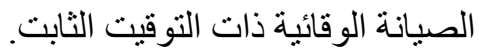

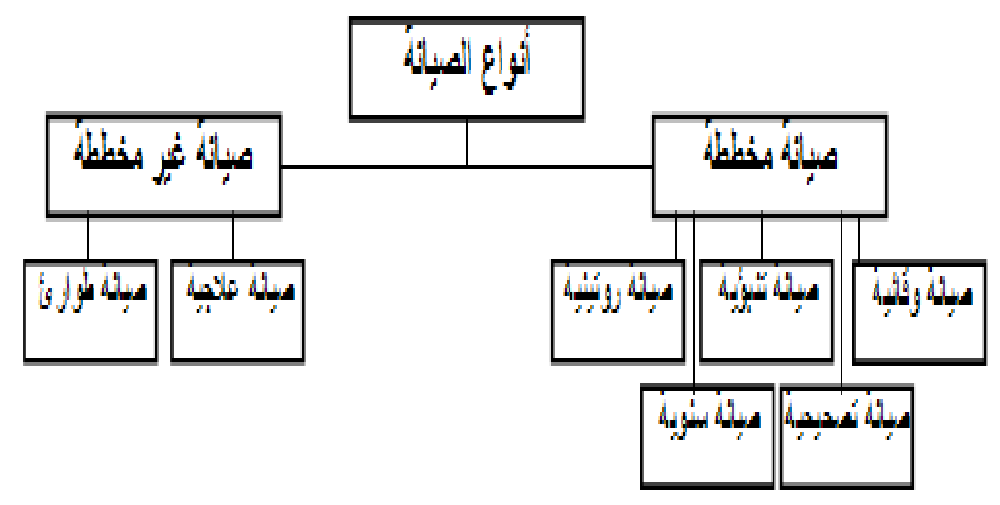

شكل (1): تصنيف يقسم أنواع الصيانة لنو عين رئيسين [المصدر: الباحث]

ج- الصيانة التصحيحية Corrective Maintenance هى أعمال الصيانة المنفذة لإعادة المبنى إلى حالته الأصلية قبل حدوث العيوب ليقيق مؤديـا وظيفته

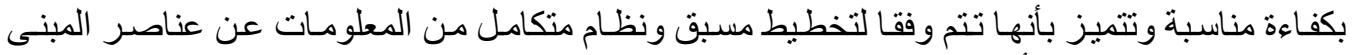

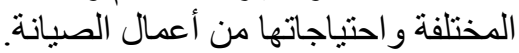

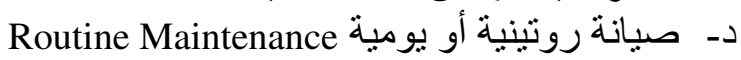

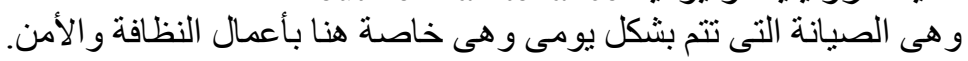
هـ- صيانة سنوية Annual Maintenance

وهى الصيانة التى تتم كل عام وهى خاصة أكثر بأعمال التشطيبات من حيث الأرضيات و الحو ائط.

Unplanned Maintenance 2.3.2. الصبانة غبر المخططة

Emergency Maintenance أـ صبانة الطوارى (الصبانة الإسعافية) هى الصيانة غير المخططة التى تتم عند حدوث أضرانة الإرئة جسيمة بالمبنى و تكون عالية التكاليف وغير متكررة و عناصر التخطيط بها غير معروفة.

Corrective Maintenance 2.3.3. الصيانة العلاجية

عرفت الصيانة العلاجية بأنها "الصيانة التى تتم بعد حدوث العيب أو الخلل و المقصود بها إعادة بند

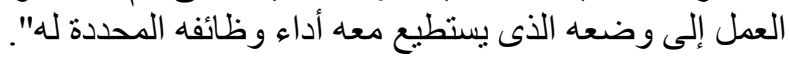

Journal of Engineering Sciences, Assiut University, Faculty of Engineering, Vol. 41, No. 2, pp. 617 -644, March, 2013,E-mail address: jes@aun.edu.eg 
هشام عثمان عبد الرحمن وآخربن - إجراءات صبيانة مبانى التعليم "المدلكة الهتحدة وجمهورية مصر العربية

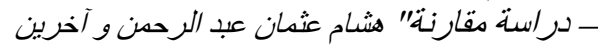

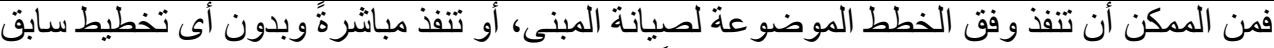
لتنفيذها فيما لو كان الإصلاح أو الاستبدال ضرورياً و عاجلاً، وبذللك تنتقل إلى نوع الصنئ الصيانة الطارئة.

\section{3. إجراءات صيانة مبانى التعليم فى المملكة المتحدة}

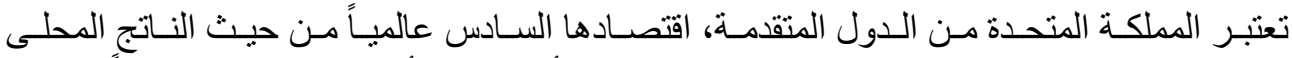

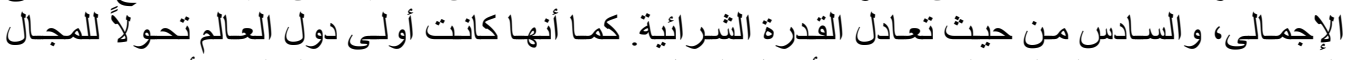

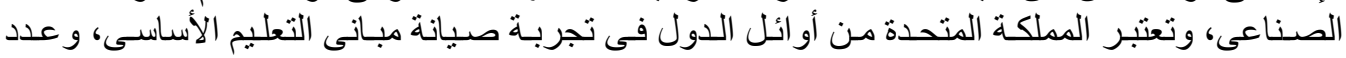

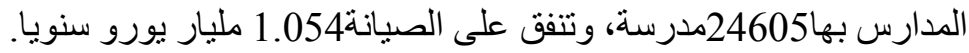

\section{1. تشربعات صبانة المبانى التعلبينة فحى المدلكة المتحدة}

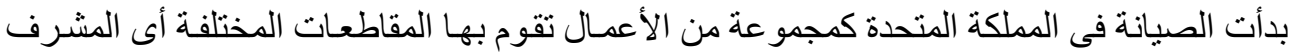
و المنفذ الرئيسى عليها هو الجهات الحكومية المحلية وذللك لجميع المدارس الحكومية.

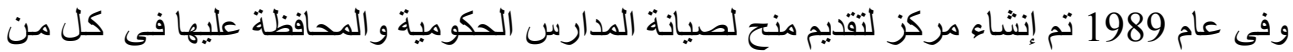

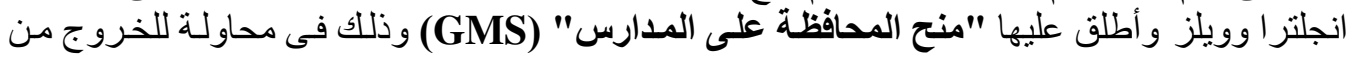

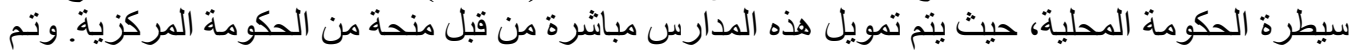

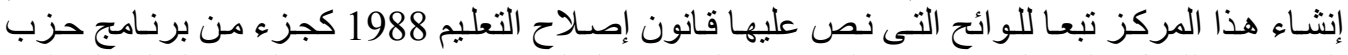

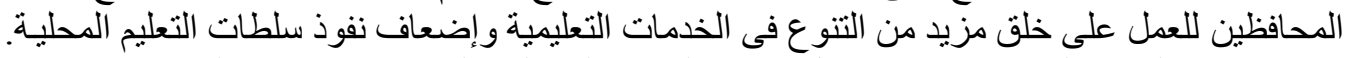

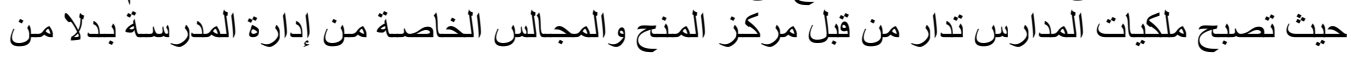
السلطة المحلية.

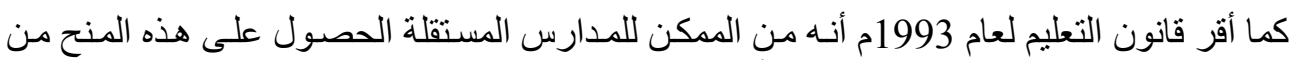

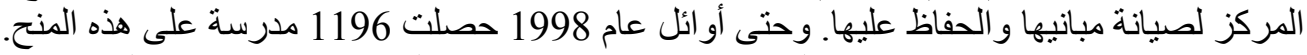

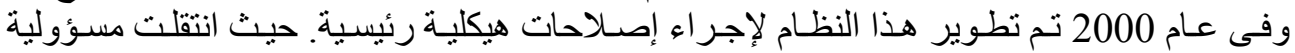

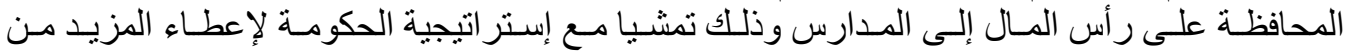
المسؤولية لمديرى المدارس لإدارة منشآتهم. ويعرف هذا في المى بعض الأحيان بالمحافظة على رأس المال.

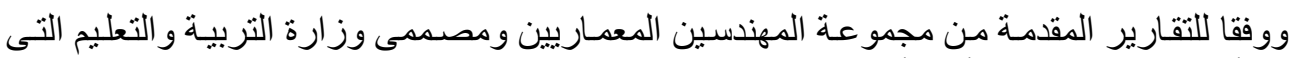

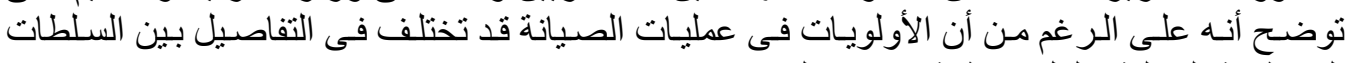

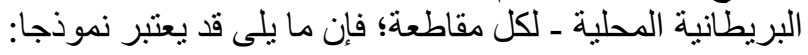

$$
\text { 3.1.1 3.1. الأولوية الأولهى }
$$

تعتبر الأولوية الأولى فى تنفيذ أعمال الصيانة كالتالى الصى

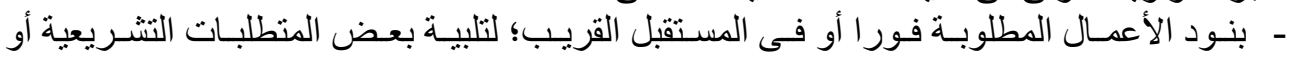
التعاقدية. - - بنود الأعمال التى تؤثر وتعمل على ضمان صحة وسلامة شاغلى المبنى و المستخدمين.

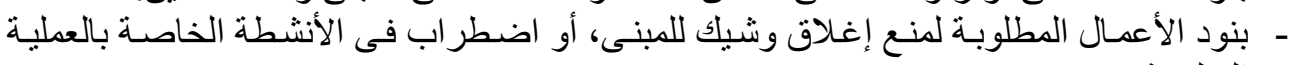
التعليمية.

Journal of Engineering Sciences, Assiut University, Faculty of Engineering, Vol. 41, No. 2, pp. 617 -644, March,2013,E-mail address: jes@aun.edu.eg 
هشام عثمان عبد الرحمن وآخربن - إجراءات صبيانة مبانى التعليم "المدلكة الهتحدة وجمهورية مصر العربية

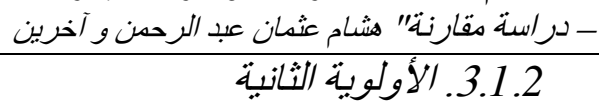

الأعمال اللازمة خلال سنة واحدة لمنع أى تدهور خطير فى المبنى أو الخدمات، مثل تلك الأعمـال

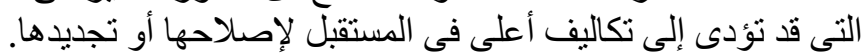
3.1.3. الأولوبية الثالثة الثئة

الأعمال التى قد تكون مؤجلة إلى ما بعد عام واحد، وهـى تتضمن الأعمـال التى تحسافظ على البيئة

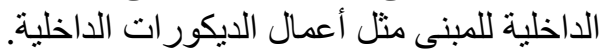

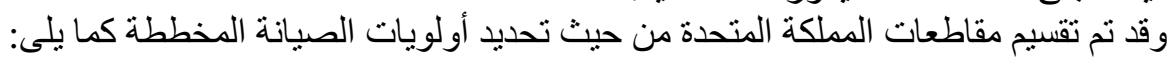

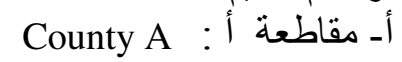

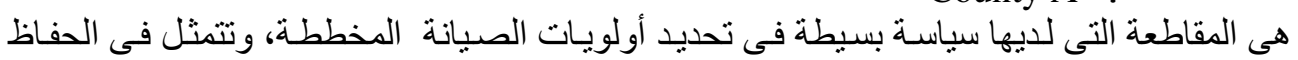

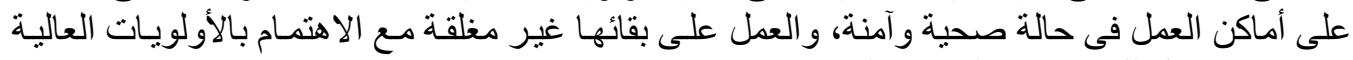
فقط من استبدال للغلايات، و السلامة الكهربة الكيائية.

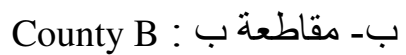

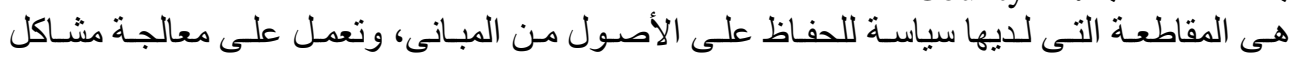

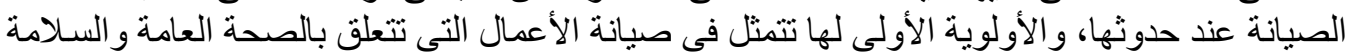

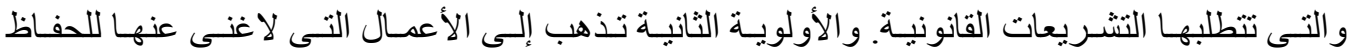

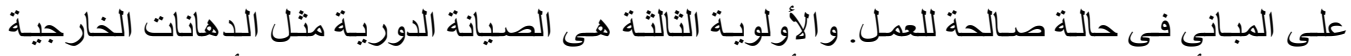

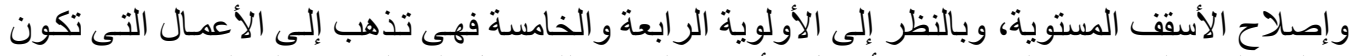

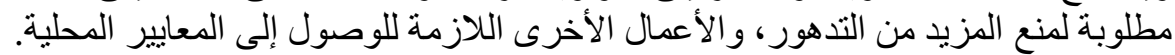

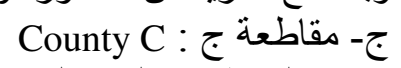

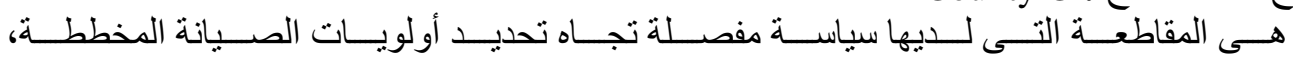

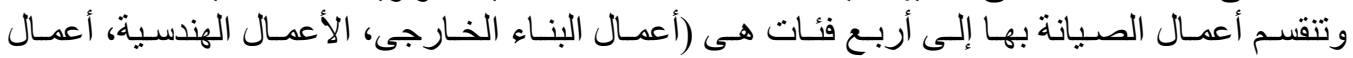

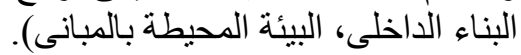
وداخل كل فئة تأتى المبادئ التوجيهية لتعبين أولويات الصيانة الصيانة كالترتيب التالى:

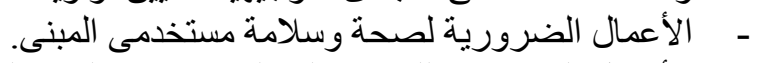

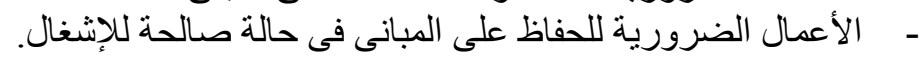

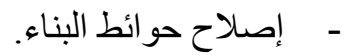

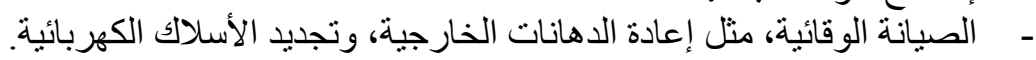

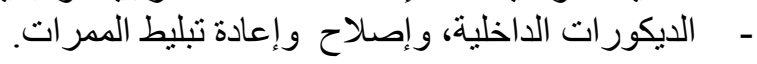

3.2. إدارة صبانة مبانسى التعلبم الأساسيى فى المملكة المتحدة

لدر اسة إدارة صسيانة مبـانى التعليم الأساسىى فى المملكة المتحدة لابـد من تحديد الأهداف الرئيسية

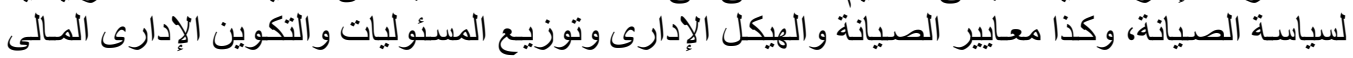
وكيفية التمويل.

3.2.1. الأ هداف الرئبيبة للصبانة الوقائية للمبانى التعلبيبة فى المدلكة المتحدة

Journal of Engineering Sciences, Assiut University, Faculty of Engineering, Vol. 41, No. 2, pp. 617 -644, March,2013,E-mail address: jes@aun.edu.eg 
هثام عثمان عبد الرحمن وآخرين - إجراءات صبيانة مبانى التعليم "المدلكة المتحدة وجدهورية مصر العربية

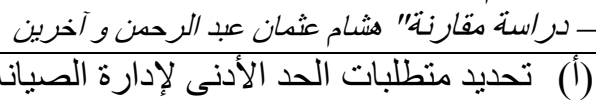
(ب) ضمان بقاء المبانى فترة كبيرة

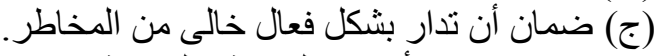

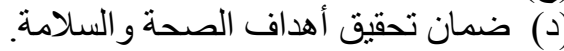

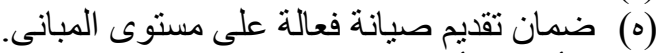

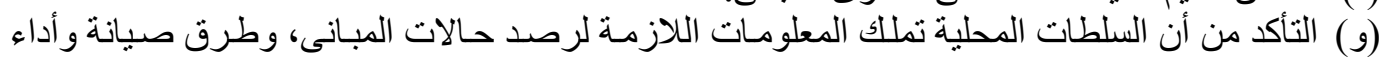

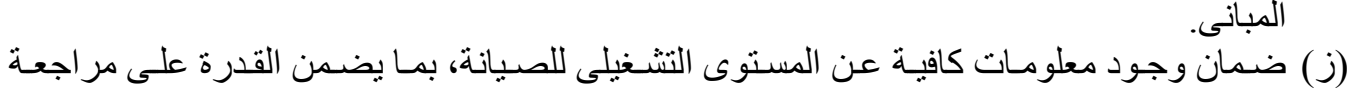
السياسات و الاستر اتيجيات، وتحليل دور ات الحياة، وخطـة الاستبدال وطرق تحسين كفاءة وفعاليـة

\subsection{2. معابير صبانة المبانسى فحى المدلكة المتحدة}

حيث يتم إتباع معايير لتحديد مدى احتيـاج المبنى لعمليات الصيانة عن طريـق عمل تقييم للصبانة

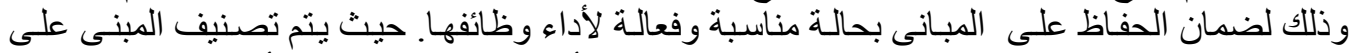

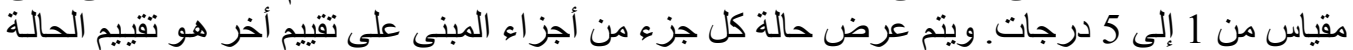

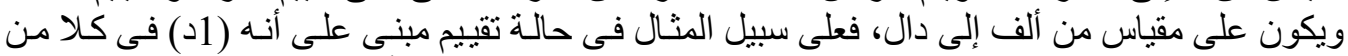

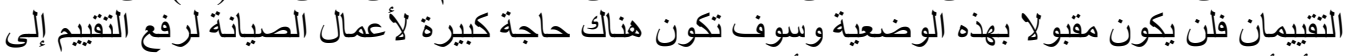

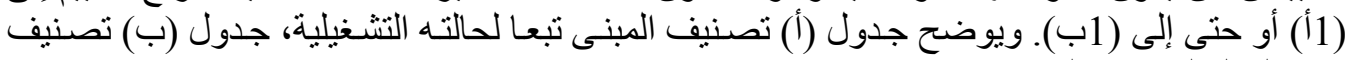
تقييم الحالة لعناصر المبنى (1)

جذول (أ): تصنيف المبانى تبعا لحالته التشغيلية [مع تصريف الباحث].

\begin{tabular}{|c|c|}
\hline تصنيف المبنى & s \\
\hline بطارية الخدمة و الأصول البنائية فى أفضل حالة ممكنة & 1 \\
\hline بطارية الخدمة والأصول البنائية فى حالة جيدة & 2 \\
\hline بطارية الخدمة و الأصول البنائية فى حالة معقولة & 3 \\
\hline لا يوجد بطارية للخدمة والأصول البنائية تلبى الحد الأدنى من الظروف التشغيلية والقانونية & 4 \\
\hline لا يوجد بطارية للذدمة، و الأصول البنائية خو اصها التشغيلية سيئة جدا & 5 \\
\hline
\end{tabular}

Journal of Engineering Sciences, Assiut University, Faculty of Engineering, Vol. 41, No. 2, pp. 617 -644, March,2013,E-mail address: jes@aun.edu.eg 
هشام عثمان عبد الرحمن وآخربن - إجراءات صيانة مبانى التعليم "المدلكة المتحدة وجدهورية مصر العربية

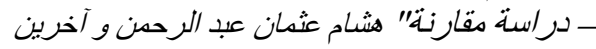

جدول (ب): تصنيف تقييم الحالة لعناصر المبنى [بالتصرف].

\begin{tabular}{|c|c|}
\hline تقييم الحالة لعناصر المبنى & s \\
\hline (جيدة) أداء على النحو المنشود، وتعمل بكفاءة & أ \\
\hline (مرضية) أداء على النحو المنشود ولكن تظهر عليها علامات تدهور طفيفة & ب \\
\hline (فقيرة) تظهر العيوب الرئيسية و / أو التى لا تعمل على النحو المنشود & ج \\
\hline (سيئة) العناصر منتهية الصلاحية و / أو وجود خطر وشيك من السقوط & د \\
\hline
\end{tabular}

ويستبعد من أعمال الصيانة الأتى:

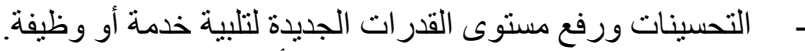
-

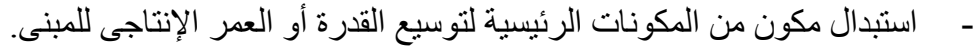

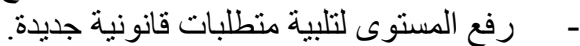

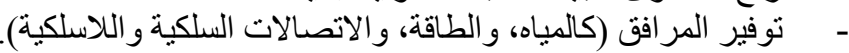
- - - - مبناء مبانى ملحقة جديدة. - الترميمات الكبيرة الناتجة عن الكوارث الطبيعية و غير ها.

3.3.الهيكل الإدارى وتوزيع المسئوليات لعملية صيانة المبانى التعليمية فى المدلكة المتحدة

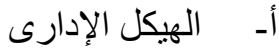

(1) إدارة المبنى: وتتكون من رئيس مجلس إدارة المبنى، ومجلس إدارة المبنى وبعض من موظفى الخدمات

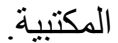

(2) إدارة الثــئون الماليــة و المـوارد: وتتكـون مـن مـدير ، ومجمو عـة وكـلاء للماليـات و المــوارد وبعض مـن

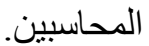

(3) فريق خدمات صيانة المبنى: و هم مجمو عة من المهندسين و الفنيين و العمال. (4) إدارة شئون التقييم و المر اجعة.

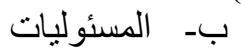

يتم توزيع المسؤولية على العناصر الرئيسية المسئولة عن المبنى كالتالى:

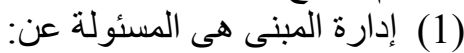
- - - - مر إدارة سياسة الصعايير الصيانة. (2) فريق خذمات الصيانة بالمبنى هو المسئول عن:

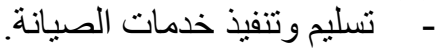

Journal of Engineering Sciences, Assiut University, Faculty of Engineering, Vol. 41, No. 2, pp. 617 -644, March, 2013,E-mail address: jes@aun.edu.eg 
تحديد ميز انية للإنفاق على أنشطة الصية الصية المخطط لها، مع الاستجابة لتحقيق المعايير المعمول

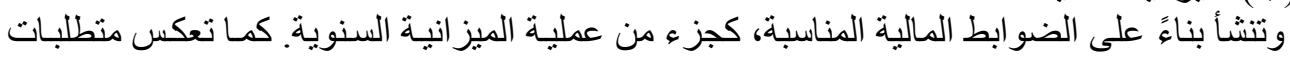

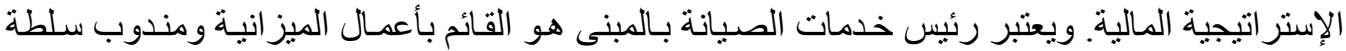
التعليم المحلية لدى المبنى لتقديم خدمات الصئة الصيانة. على أن يتم تحديد رأس المال و عائدات المو ارد لخمس سـنوات، كمـا تهدف در استهـة ميز انيـة الصيانة

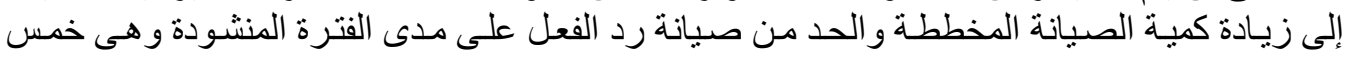

وتختلف تكاليف وميزانية الصيانة بـاختلاف تصميم و عمر المدرسـة، ومدى توافر الموارد اللازمـة

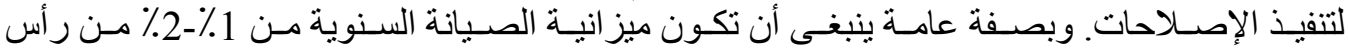
المال. وفى بعض الحالات يتم تفويض المجتمع المدرسى مسؤولية المحافظة على المر افق المدرسية. ولذئة الذانة

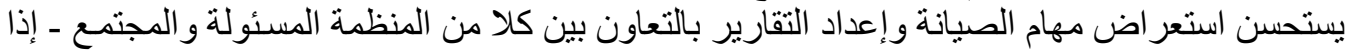

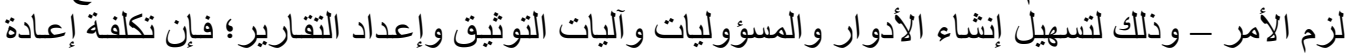

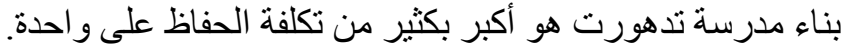

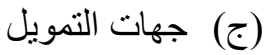
تتمثل جهات التمويل فى المملكة المتحدة في: 
هثام عثمان عبد الرحمن وآخربن - إجراءات صيانة مبانى التعليم "المدلكة المتحدة وجدهورية مصر العربية

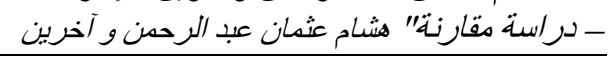

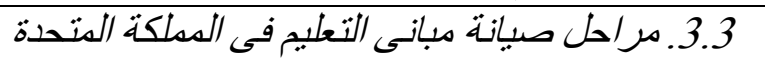

وتعتبر مر احل صبانة مبانى التعليم المطبقة فى المملكة المتحدة هيى مجمو عة من الخطوات تقوم بها

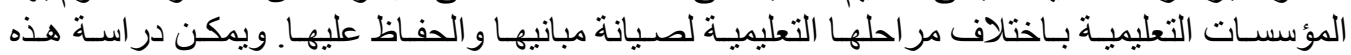
المر احل المختلفة وكيفية صياغتها عن طريق در اسة العناصر الآتية.

$$
\text { 3.3.1. برنامج صبانة المدارس }
$$

ويتكون برنـامج صسيانة المدارس من ثناثة عناصـر رئيسية هـى: مسئولو التنظيم، خطـة الصيانة (جدولة التفتيش)، التقبيم.

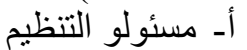
ويعتبر مسئولو التنظيم هم البنيـة الأساسية التنظيميـة ويتكونو المن المنسف العـام والأفر اد أو الفرق المسئولة عن مناطق الصبيانة في المدرسة.

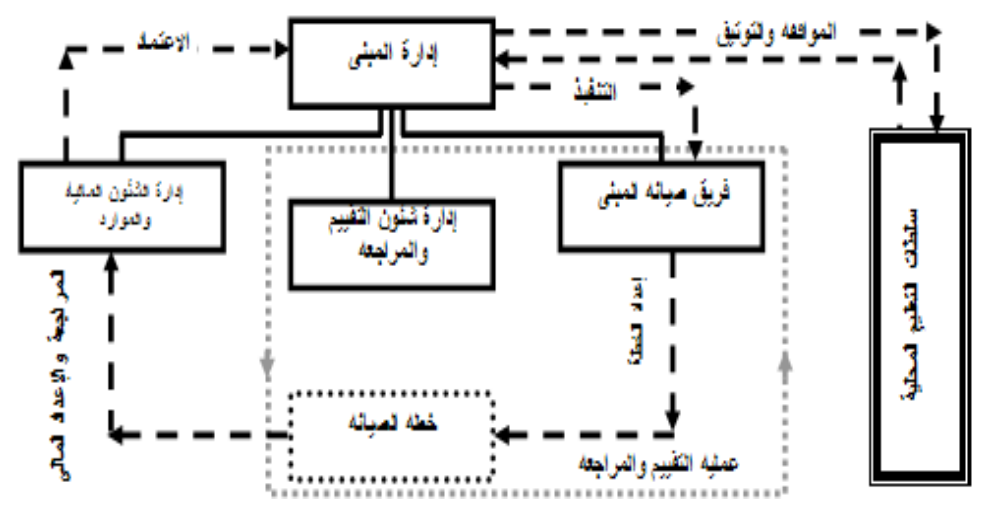

[المصدل (الباحث]: خطو ات إعداد خطة صيانة المبانى التعليمية بالمملكة المتحدة وعلاقتها بالهيكل الإدارى ب- بطة الصيانة ونتألف خطـة الصيانة من جدولة لعمليـات التفتيش، والأطر اف المسئولة، ونقاط التفتيش و التدابير

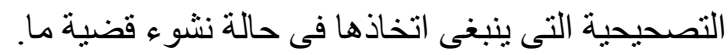
ج- التقبيم

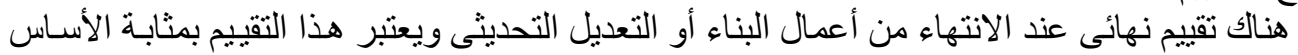

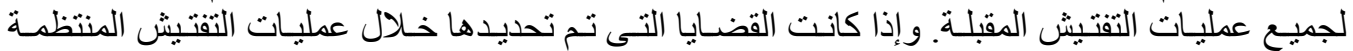

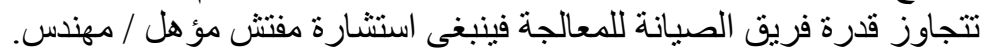
3.3.2. مصفوفة صبانتة المبانسى

Journal of Engineering Sciences, Assiut University, Faculty of Engineering, Vol. 41, No. 2, pp. 617 -644, March,2013,E-mail address: jes@aun.edu.eg 
هشام عثمان عبد الرحمن وآخربن - إجراءات صبيانة مبانى التعليم "المدلكة الهتحدة وجمهورية مصر العربية

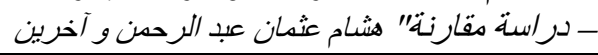

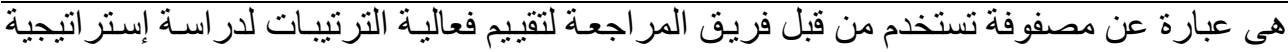

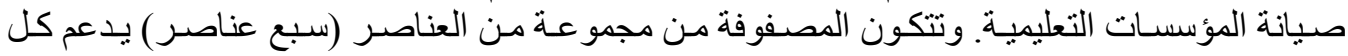

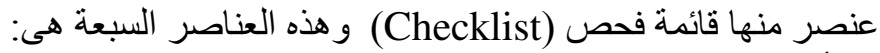

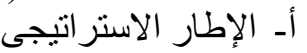

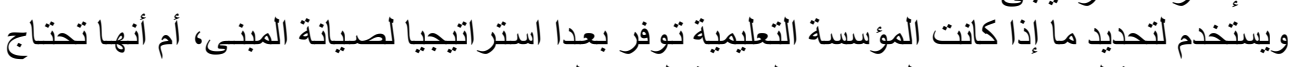
لوضع إستر اتيجية لتحقيق نهج فعال ومنسق لصيانة المبانى لديها.

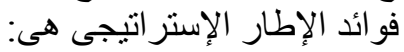

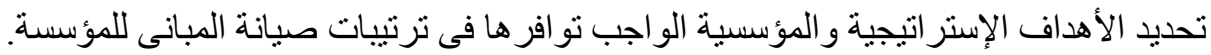

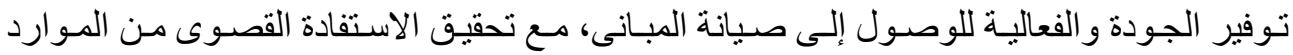

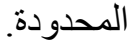

تحديد المسؤوليات الإدارية و الأهداف بطريقة و اضحة.

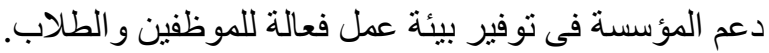
ب- تقبيم الوضع الر اهن (در استة الحالة)

وتستخدم لتحديد ما إذا كانت المؤسسة تقوم باستخدام المرام المسح المبدانى لدر اسة حالة مبانيها المختلفة.

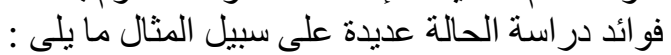

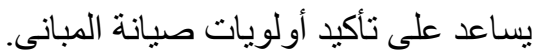

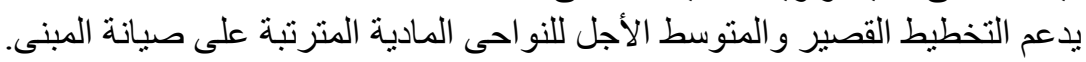
يوفر معلومات قيمة حول التأثير الفعلى للترتيبات الحالية. ج-تخطيط الصيانة

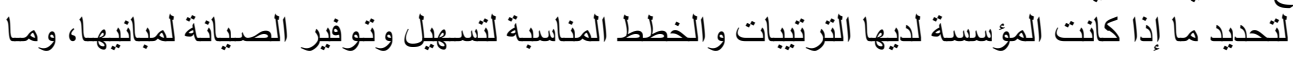
يرتبط بها من الخدمات الميكانيكية و الكهربائية، بما فى ذلك الأعمال البسيطة، و عمليات التجديد الرئيسية. فو ائد تخطيط الصيانة هنى ضمان تحديد فعال لاحتياجات صيانة فيانة المبانى.

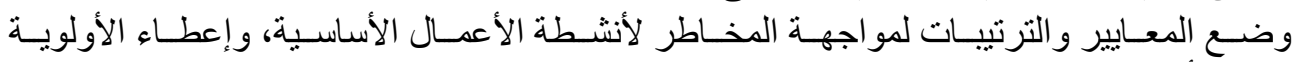
الإنجاز أعمال الصيانة ودعم معايير الخدمة التيبرة المعتمدة.

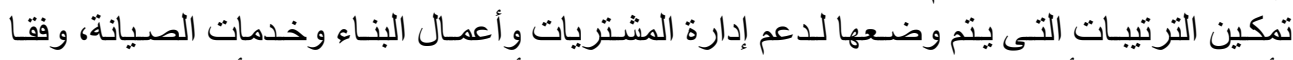

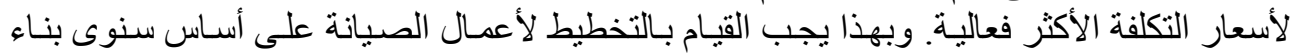

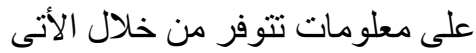

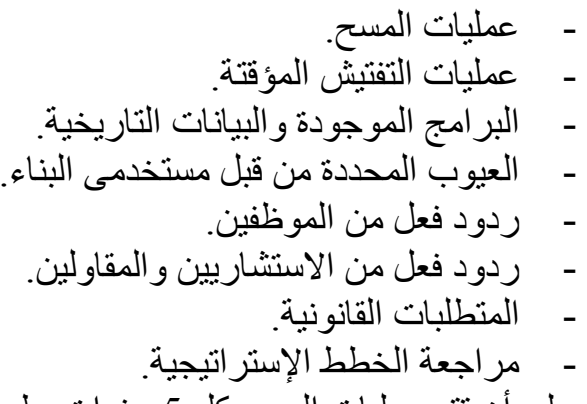

على أن تتم عمليات المسح كل 5 سنوات بطريقة تفصيلية وتتم كل سنة بطريقة غير تفصيلية.

Journal of Engineering Sciences, Assiut University, Faculty of Engineering, Vol. 41, No. 2, pp. 617 -644, March, 2013,E-mail address: jes@aun.edu.eg 
هشام عثمان عبد الرحمن وآخربن - إجراءات صيانة مبانى التعليم "المدلكة المتحدة وجدهورية مصر العربية

- دراسة مقارنة" هشام عثمان عبد الرحمن و آخربين

د- تخطيط الموارد

تستخدم لتحديد كيف تقوم المؤسسـة بتوفير التمويل لتقديم الأولويـة لأعمال صيانة المبنى، كمـا هو

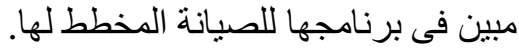

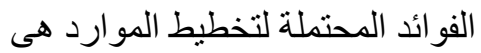
تحديد " قمم" و "قيعان" نفقات صيانة المبانى وجعلها متو ازنة وفقا للموارد التهن المتاحة.

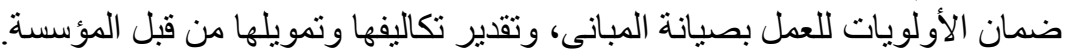

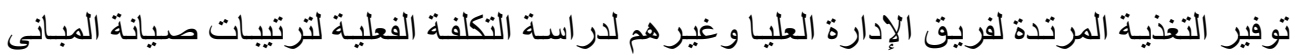
و الاستفادة منها فى التخطيط الجدئ.

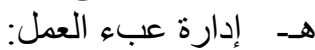

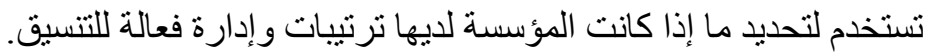

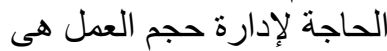

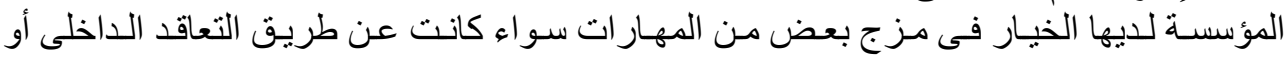

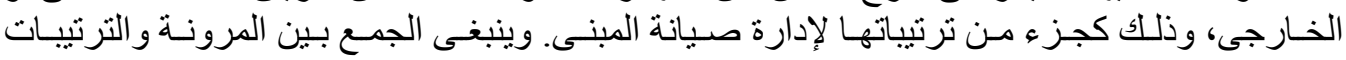

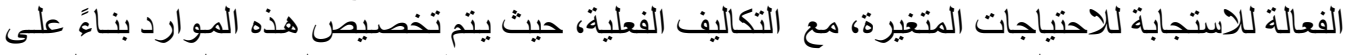

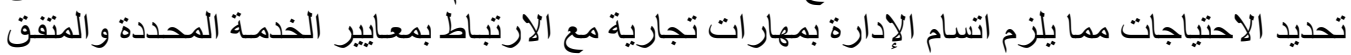

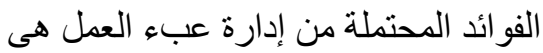

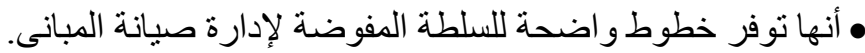
• تمكن من الاتفـاق على معـايير مستوى الخدمـة لتوفير مستويات محددة من الخدمـة و التسـليم مـن قبـل المؤسسة. • تمكن المؤسسة من تحديد أهداف الجودة ورصد التقدم المحرز فى بناء أعمال الصيانة.

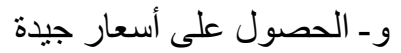
لتحديد طرق تقييم السوق التنافية من حيث تكلفة أعمال الصيانة للمبنى التى يقوم بها مقدمى التعاقد.

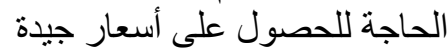

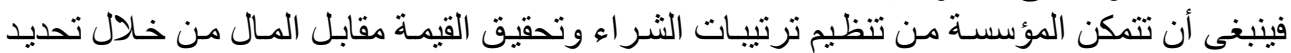

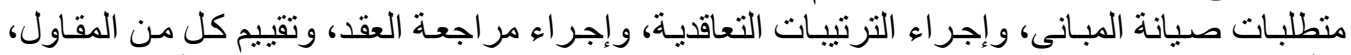

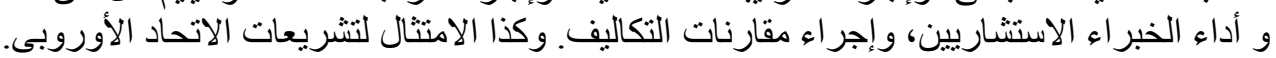

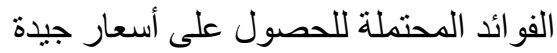

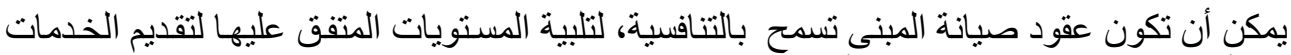

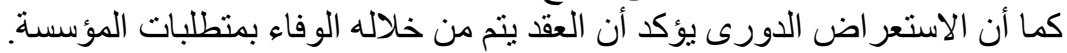
يمكن للمؤسسة شر ح القيمة افئم مقابل المال. ز - تقبيم الجودة لتحديد ما إذا كان لدى المؤسسة ترتيبات بشأن معايير الخدمة لتقديم أعمال الصيانة المبنى.

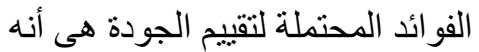

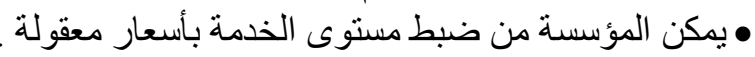

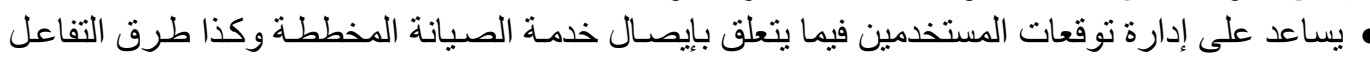

Journal of Engineering Sciences, Assiut University, Faculty of Engineering, Vol. 41, No. 2, pp. 617 -644, March,2013,E-mail address: jes@aun.edu.eg 
هشام عثمان عبد الرحمن وآخربن - إجراءات صبيانة مبانى التعليم "المدلكة الهتحدة وجمهورية مصر العربية

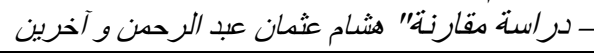

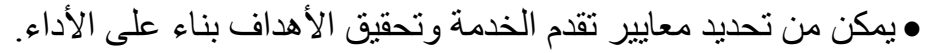

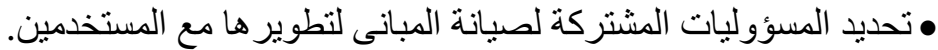

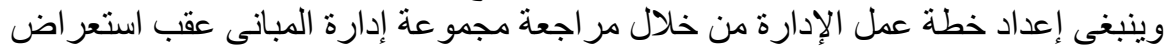

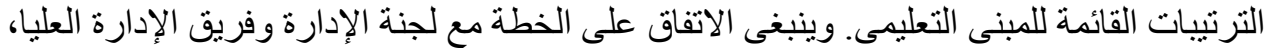

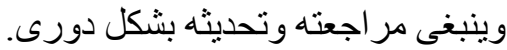

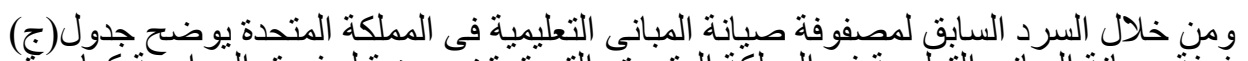

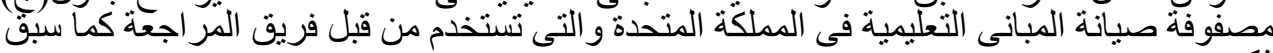

3.3 .3

يتم تحديد ونوزيع بنود خطة الصيانة ضمن برنامج مدته (10) سنو ات ويتم صياغته من خلال النقاط التالية:

$$
\text { - }
$$

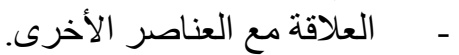

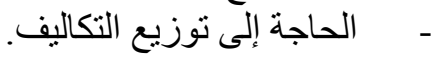

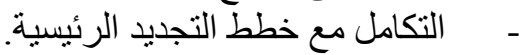

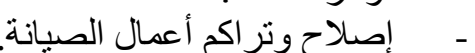

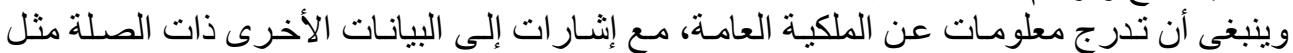

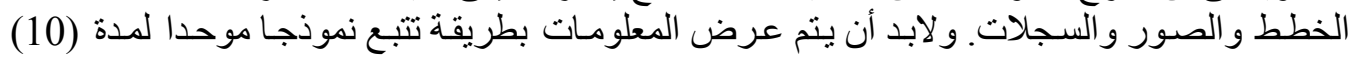

سنو ات وتشتمل على ما يلى ورئ:

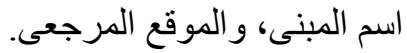
العنصر وتفاصيل المكونات. كود الحالة. وصف العمل المطلوب. علامة تحدد الأولويات. القيمة.

السنة التى يتم العمل على تتفيذها. ويمكن استخدام عمود الأولوية لتحديد ما يلى : لئهل - البنود العاجلة التخدام

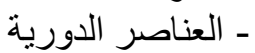
ـ ـ البنود الواردة في عقود الخدمة الإدة. ـ ـ الإصلاحات المتر اكمة. ـ الامتثال للتشريعات القانونية.

Journal of Engineering Sciences, Assiut University, Faculty of Engineering, Vol. 41, No. 2, pp. 617 -644, March, 2013,E-mail address: jes@aun.edu.eg 


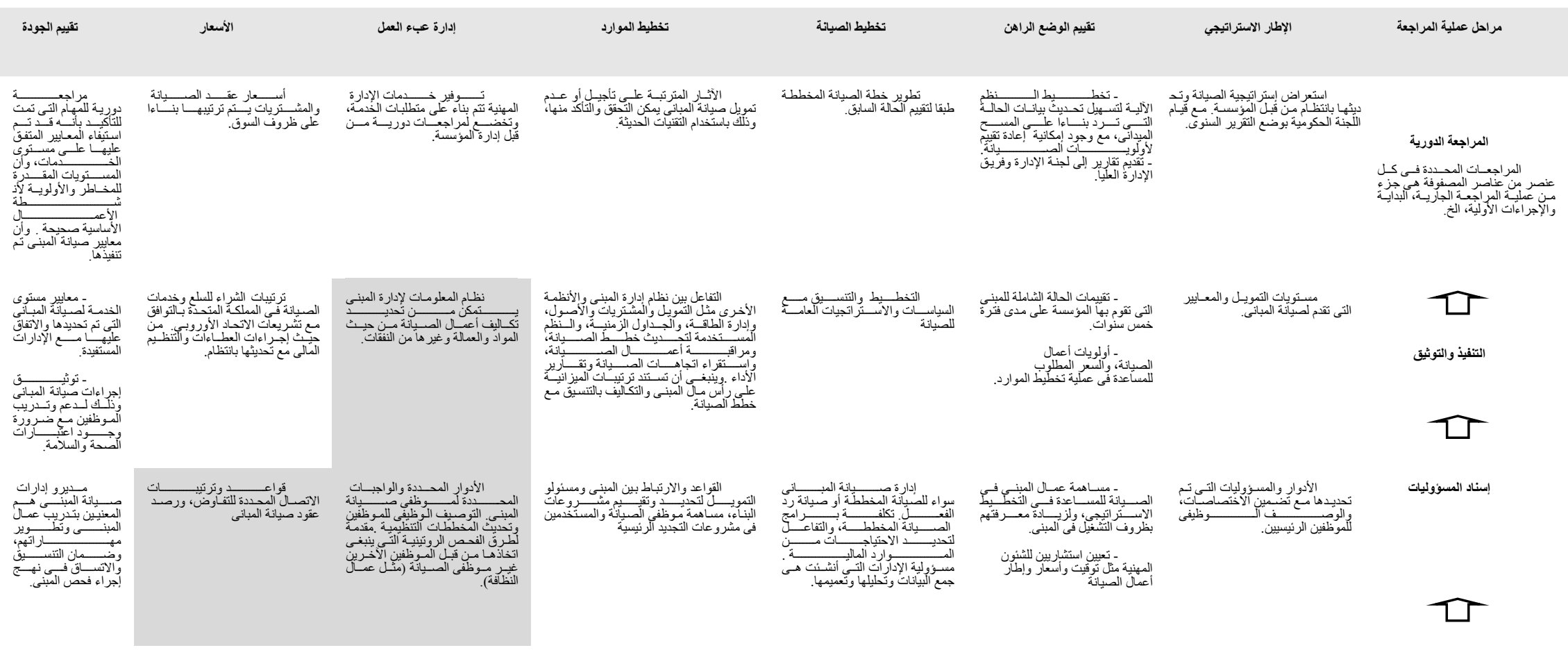


هشام عثمان عبد الرحمن وآخربن - إجراءات صبانة مبانسى التعليم "المدلكة المتحدة وجمهورية مصر العربية ـ دراسة مقارنة" هثام عثمان عبد الرحمن و آخربن

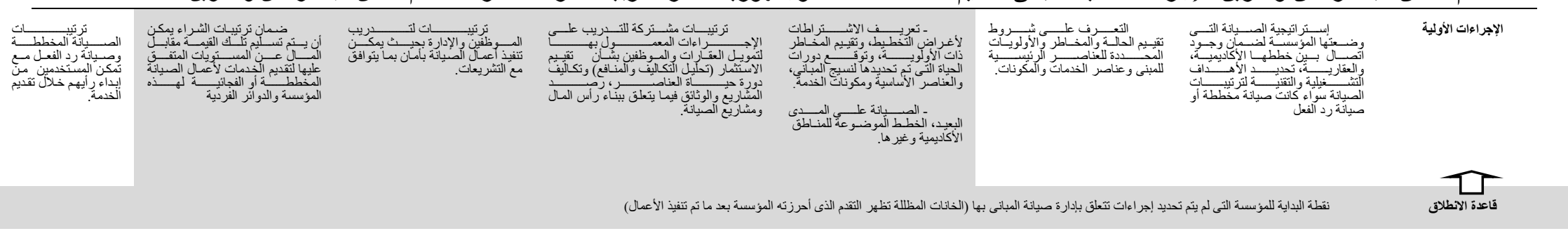

$\overline{\text { Journal of Engineering Sciences, Assiut University, Faculty of Engineering, Vol. 41, No. 2, pp. } 617 \text { - 644, March, 2013, E-mail address: jes@aun.edu.eg }}$ 
هشام عثمان عبد الرحمن وآخربن - إجراءات صبانة مبانى التعليم "المعلكة المتحدة وجههورية مصر العربية -

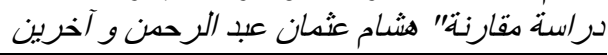

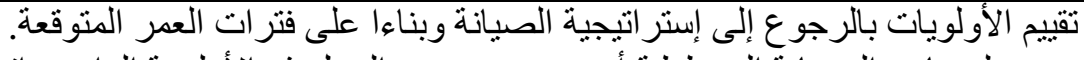

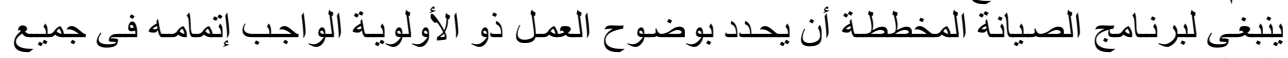
التكاليف.

لابد من ضبط التوقيتات عن طريق التفتيش للتأكد من البيانات، على سبيل المثنال، برمجـة جميع

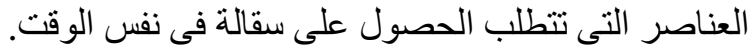

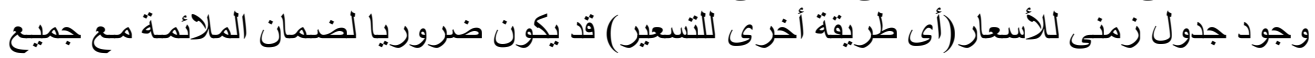
المبانى.

التر ابط مع قاعدة بيانات التكلفة لتسهيل التحديث المنتظم للمعلومات المالية.

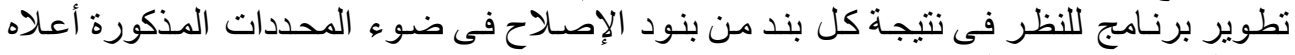
ومتطلبات إستر اتيجية الصيانة. 3.3 .4 جدول العدر الافتراضسى للمكونات

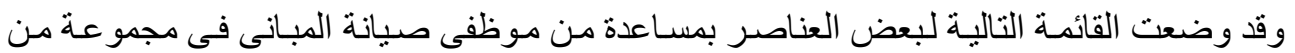

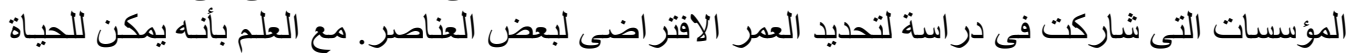

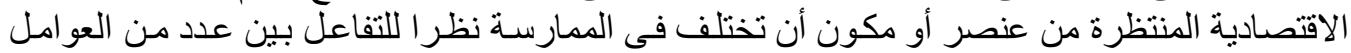
المادية و البيئية و التشغيل. ويوضنح جدول ملئ (د) العمر الافتر اضى لبعض فون مكونات المبنى.

جدول(د): العمر الافتر اضى لبعض مكونات المبنى[13] [مع تصريف الباحث].

\begin{tabular}{|c|c|c|c|}
\hline العمر المتوقع/سنة & 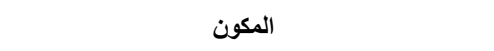 & العمر المتوقع/سنة & المكون - ان \\
\hline & التوصيلات الكهريائية الرئيسية (الذارجية) & & 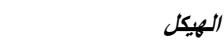 \\
\hline $35-30$ & الكابلات تحت الأرض، والكابلات MICC & $60-50$ & العنصر الإنشائى العى \\
\hline 25 & الخطوط الهو ائية، الكابلات الدغلفة البلاستيكية، & 25 & التكسيات \\
\hline 30 & التوصبلات الكهربائية الداخلية & 30 & 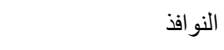 \\
\hline 30 & مفتاتيح التوزيع(فئى الأماكن الدغلقة) الأسلاك، ولوحات & 10 & تكسية الأرضيات \\
\hline 20 & 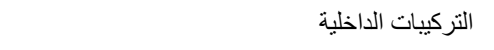 & 6 & 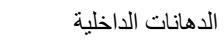 \\
\hline 15 & 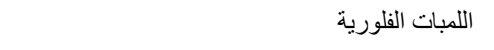 & 5 & 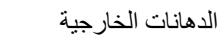 \\
\hline 10 & ل لعبات التنجستين & & التركييات المائية \\
\hline 20 & تجهيزات إضاءة الشوارع & 20 & الأنابيب فى مجارى سنة \\
\hline
\end{tabular}

Journal of Engineering Sciences, Assiut University, Faculty of Engineering, Vol. 41, No. 2, pp. 617 -644, March, 2013,E-mail address: jes@aun.edu.eg 
هشام عثمان عبد الرحمن وآخربن - إجراءات صيانة مبانى التعليم "المدلكة المتحدة وجدهورية مصر العربية

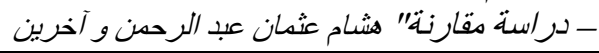

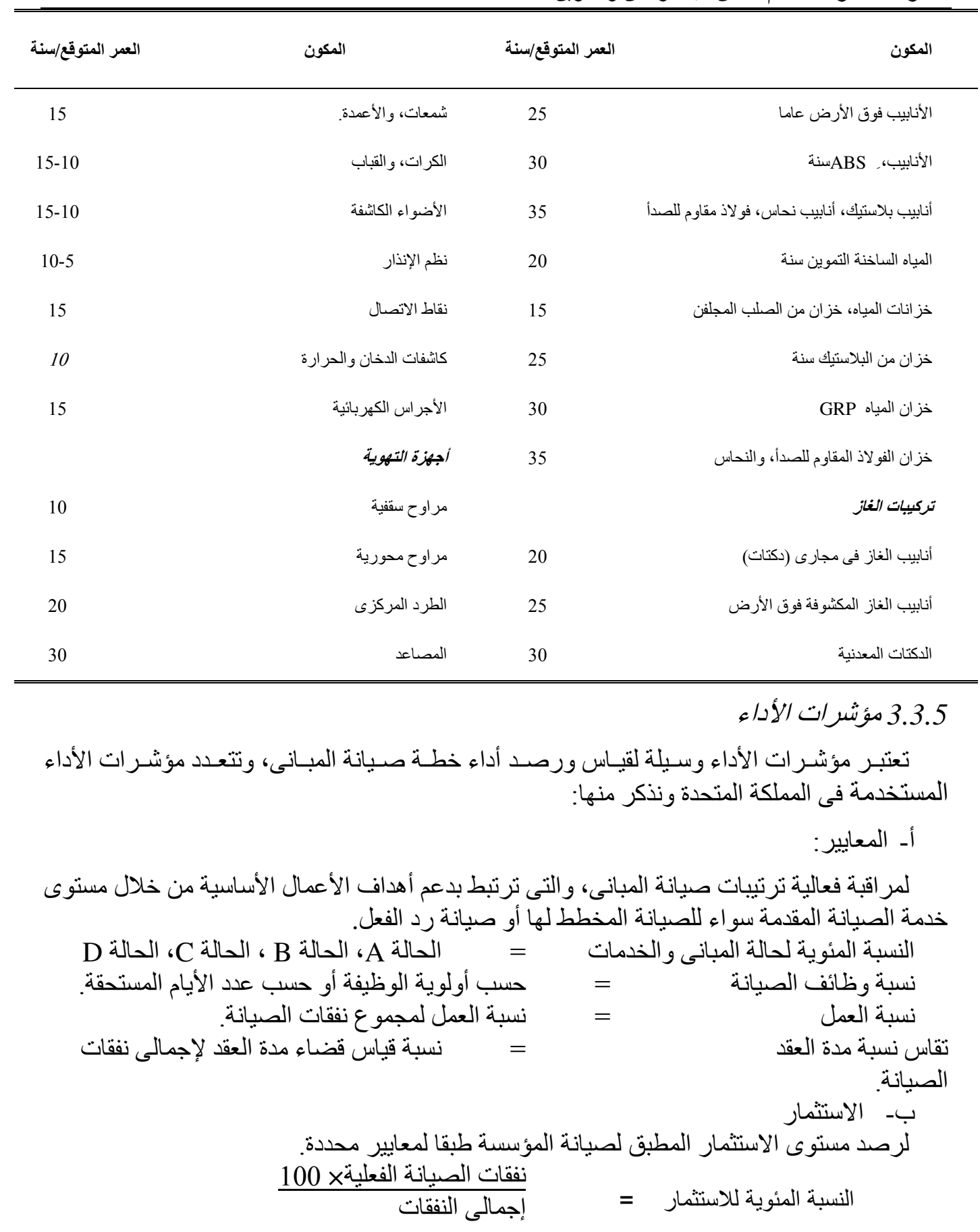

Journal of Engineering Sciences, Assiut University, Faculty of Engineering, Vol. 41, No. 2, pp. 617 -644, March, 2013,E-mail address: jes@aun.edu.eg 


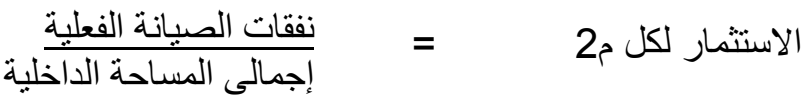

$$
\begin{aligned}
& \text { الاستثمار لمجموع طاقم عمل الصيانة= علفق طات الصيانة الفعلية الصيانة }
\end{aligned}
$$

$$
\begin{aligned}
& \text { ج-التخطيط } \\
& \text { رصد المستوى الفعلى لصيانة المبنى مقابل المستويات المخططة للصبانة. }
\end{aligned}
$$

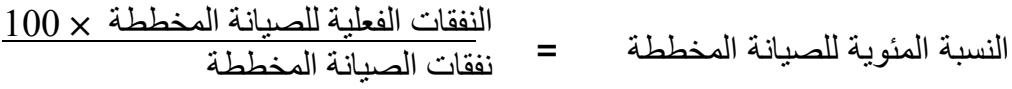

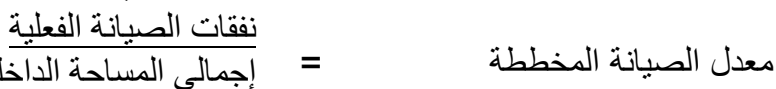

نسبة نفقات الصيانة المخططة لسبة نفقات الصيانة المخططة إلى نفقات صيانة رد الفعل د- طاقم الموظفين

رصد وتخصيص الموارد البشرية المناسبة للوصول إلى المستوى المطلوب من الصيانة المخططة

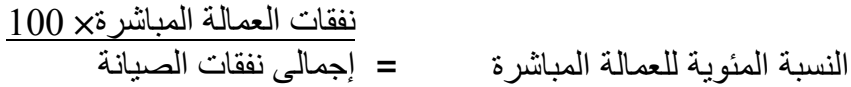

$$
\begin{aligned}
& \text { نفقات العمالة المباشرة التعانة } \\
& \text { نسبة القوى العاملة فى الصيانة نفقات التعاقدات الخارجية للصيانة }
\end{aligned}
$$

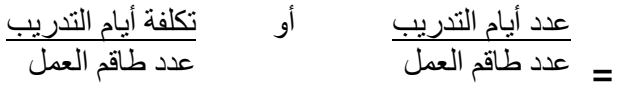

$$
\begin{aligned}
& \text { من قبل القوى العاملة المدربة. } \\
& \text { الحالة التدريبية للطاقم }
\end{aligned}
$$

\section{4. إجراعات صيانة مبانى التعليم الأساسى فى جمهورية مصر العربية}

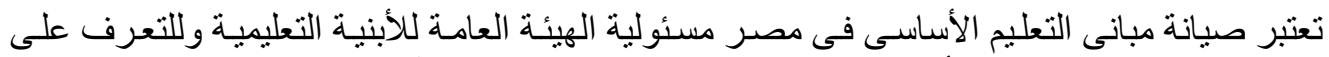

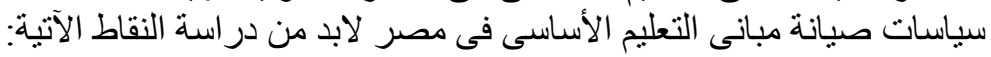

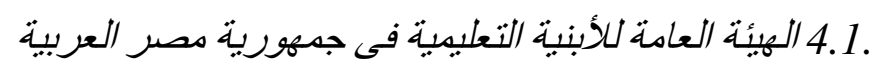
بدأت الهيئة العامة للأبنية التعليمية فى ممارسة نشساطها فى يوليو 1990م فى خمس محافظسات ثم

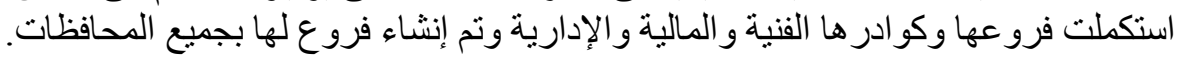

$$
\text { 4.1.1 أهداف العيئة }
$$

تهدف الهيئة إلى وضع وتتفيذ خطة للاستيعاب الكامل للتلاميذ فى كافة الفئات العمرية فى السلم

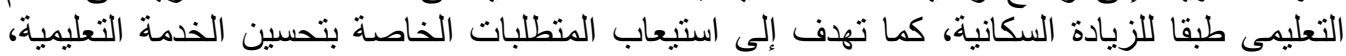

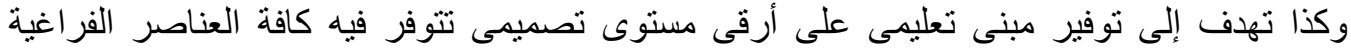

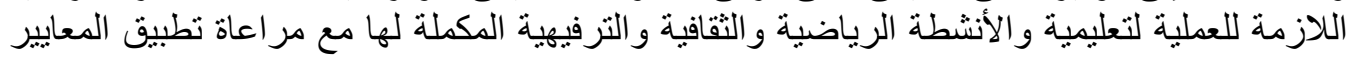
الوظيفية و البيئية و التربوية لائية الصحيحة.

Journal of Engineering Sciences, Assiut University, Faculty of Engineering, Vol. 41, No. 2, pp. 617 -644, March,2013,E-mail address: jes@aun.edu.eg 
هشام عثمان عبد الرحمن وآخربن - إجراءات صيانة مبانى التعليم "المدلكة المتحدة وجدهورية مصر العربية

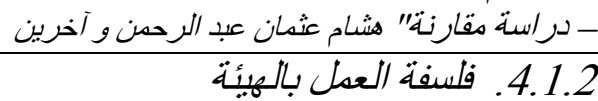

انتهجت الهيئة فلسفة إتباع أسس علمية مدروسة لوضع الإطار العام والخطط والخطوات و الإجر اءات اللازمة لتحقيق التطوير و الإصلاح المطلوب للعملية التعليمية.

أما عن فلسفة إدارة الأعمال التنفيذية فى إنشاء مبانى مدرسية جديدة فهى ترتكز على قيام الهيئة بإنشاء

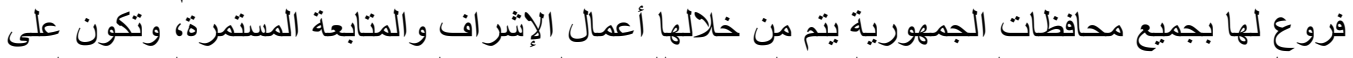

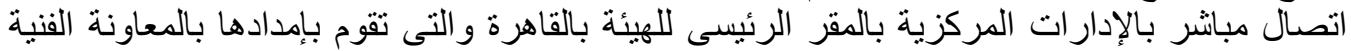
و الإدارية.

\subsection{3. مجالات عمل الهيئة}

أـ ـ وضع تخطيط علمى عام للمبانى التعليمية باستخدام الخريطة المدرسية - وذللك على مستوى الته

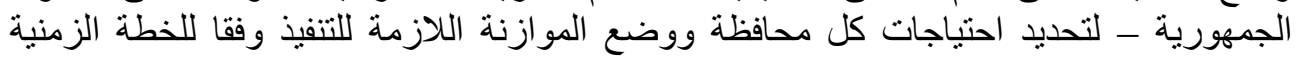

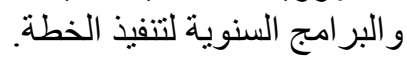
بـ إعداد الدر اسات اللازمة لتطويز التذّة معايير ومو اصفات تصميم المبانى التعليمية وفقا للأساليب التربوية

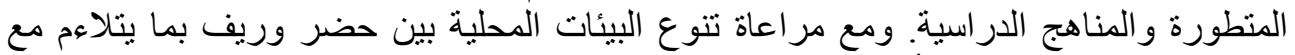

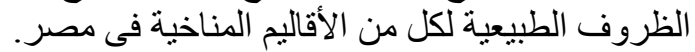

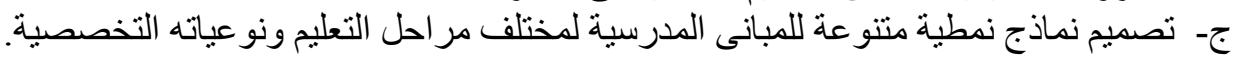

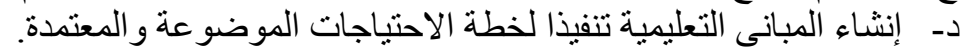

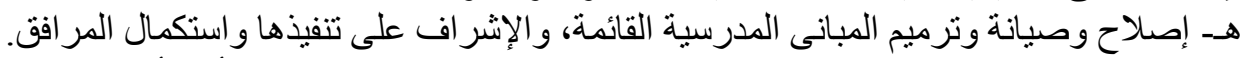

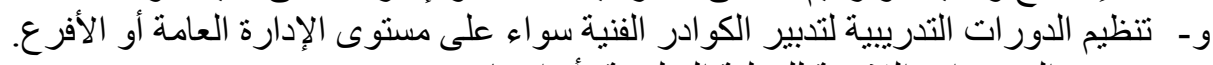
ز- تصميم التجهيز ات اللازمة للعملية التعليمية بأنو اعها.

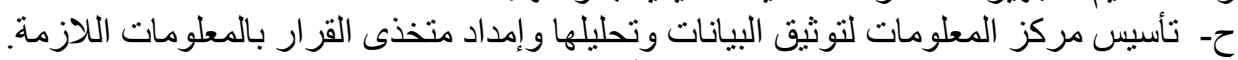

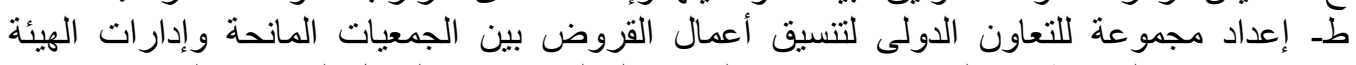

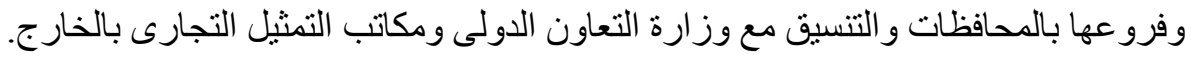

4.1.4 العبكل التنظبيسى للعيئة

فى سبيل قيام الهيئة بالمسئوليات و المهام الموكلة إليها تم وضع الهيكل التنظيمى للهيئة. ويوضح الثكل (3) الهيكل التنظيمى للهيئة العامة للأبنية التعليمية.

Journal of Engineering Sciences, Assiut University, Faculty of Engineering, Vol. 41, No. 2, pp. 617 -644, March,2013,E-mail address: jes@aun.edu.eg 
هشام عثمان عبد الرحمن وآخربن - إجراءات صيانة مبانى التعليم "المدلكة المتحدة وجدهورية مصر العربية - دراسة مقارنة" هثام عثمان عبد الرحمن و آخرين أرين
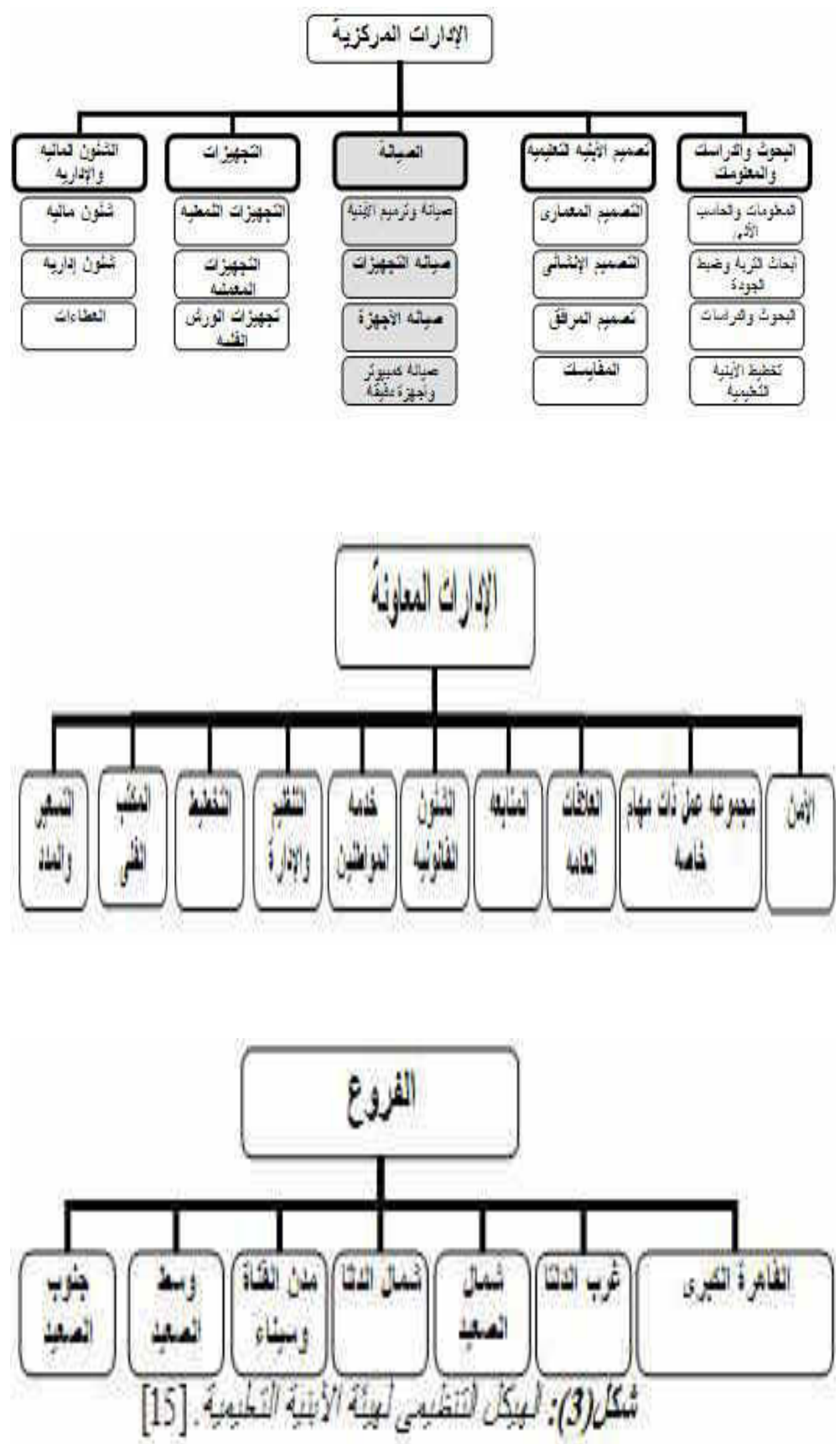

Journal of Engineering Sciences, Assiut University, Faculty of Engineering, Vol. 41, No. 2, pp. 617 -644, March, 2013,E-mail address: jes@aun.edu.eg 


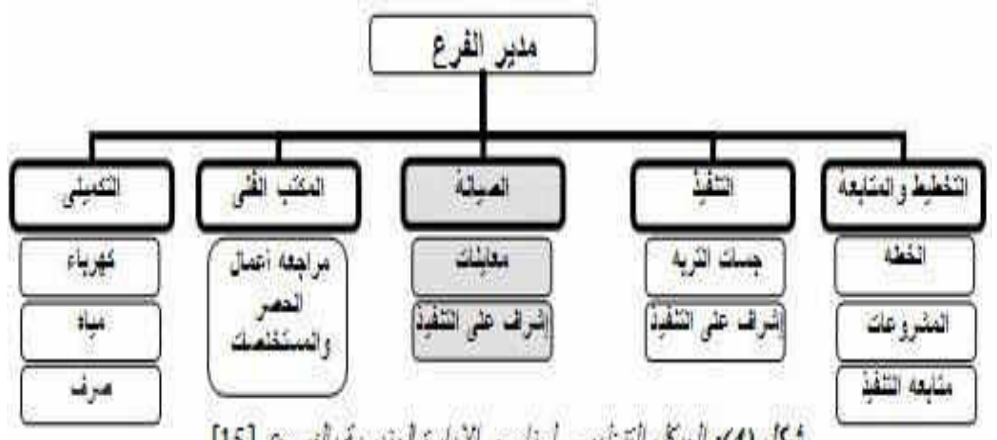

[15].

4.1.5

و هى التشريعات الخاصة بأعمال الهيئة العامة للأبنية التعليمية فقد صدر القرار الوزارى رقم (200)

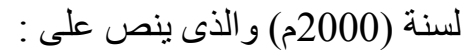

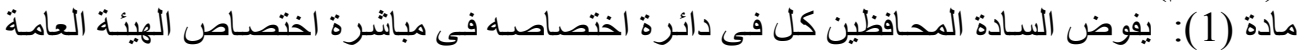

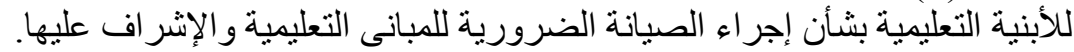

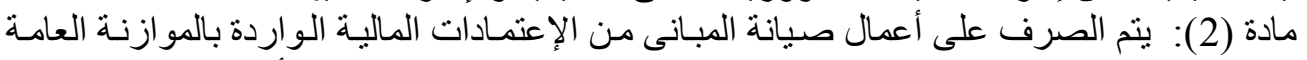

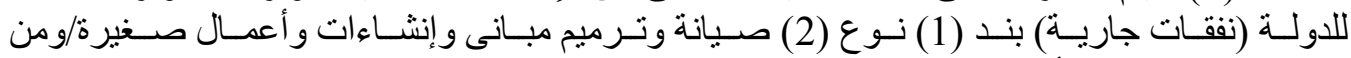

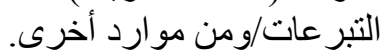
مادة (3): يجوز للأجهزة المختصة بالمحافظات المات عند اتخاذ اللازم لتنفيذ أعمال صيانة المبانى

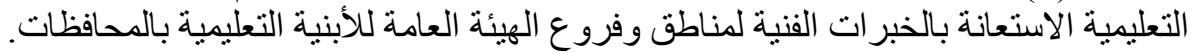

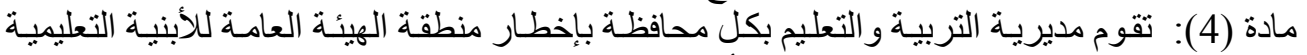

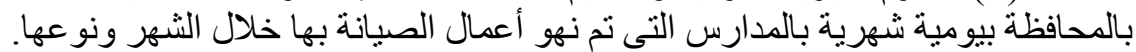

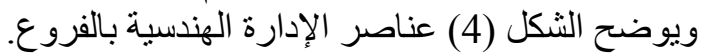

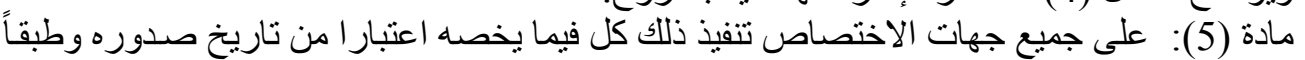

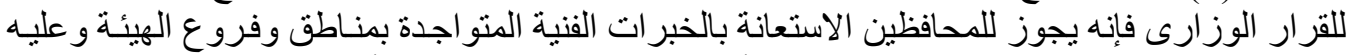

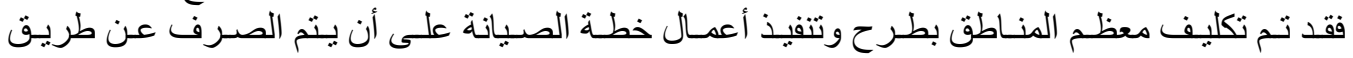
المحافظات.

$$
\text { 4.1.6 . جهات التموبيل }
$$

تتعد جهات التمويل للهيئة العامة للأبنية التعليمية سو اء كان هذا التمويل ينفق على عمليات الإنشـاء أو

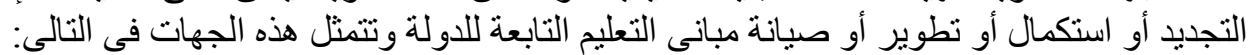

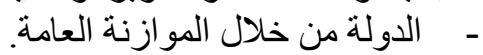
- منح البنك الدولى. -

Journal of Engineering Sciences, Assiut University, Faculty of Engineering, Vol. 41, No. 2, pp. 617 -644, March,2013,E-mail address: jes@aun.edu.eg 


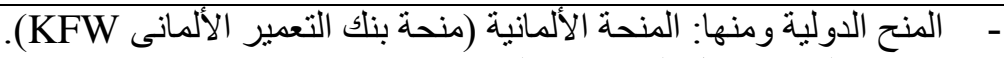

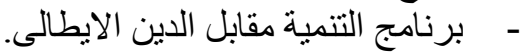

4.2. إستر/تيجية الصبانة وأساليب وبر/مج التطبيق:

يمكن دراسة إستر اتيجية الصيانة من خلال الأتى:

$$
\text { أنواع الصبانة }
$$

قامت الهيئة العامة للأبنية التعليمية بوضع تقسيم لأنظمة الصيانة للأبنية التعليمية كالتالى:

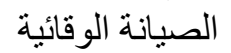

يقصد بهذا النوع من الصيانة، العمل على إنتاج منشأ يتميز بالقوة و المتانة واستيفاء متطلبات الاستخدام

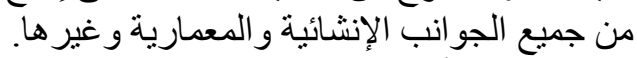

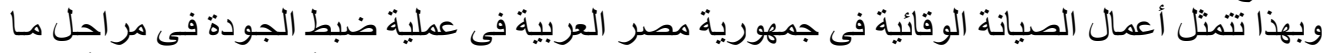

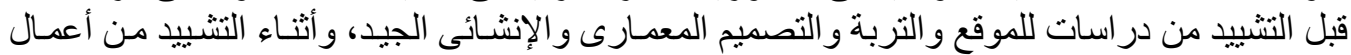

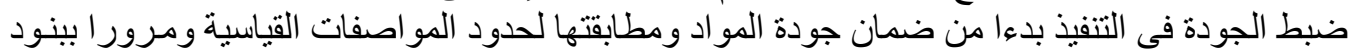

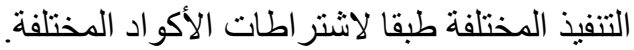

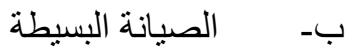

هى تتم من خلال التفتيش اليومى على حالـة المبنى و الأعمـال التكميلية الظـاهرة، و التىى بكون مسئولا

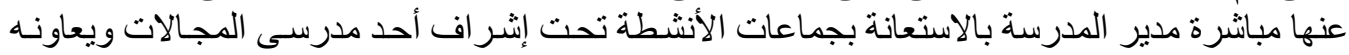

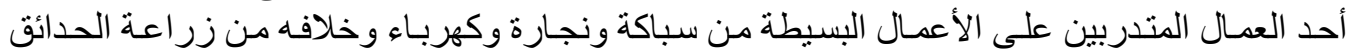

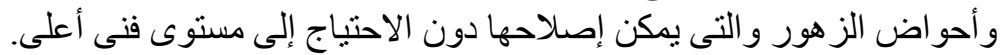

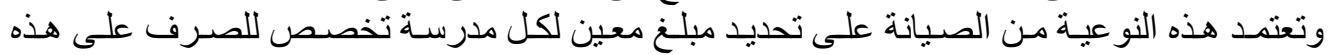
الأعمال البسيطة بجانب مخزو هند من من احتياجات هذه النو عية من الصيانة.

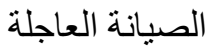

من خلال التفتيش اليومى على العلى حالة المبنى والأعمال التكميلية الظاهرة قد يتضـح وجود عيوب تستلزم

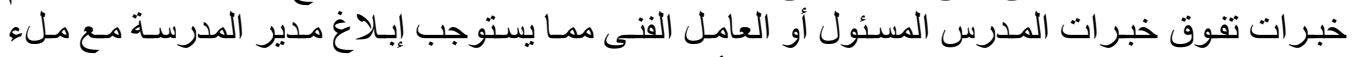

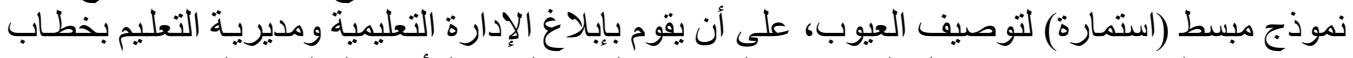

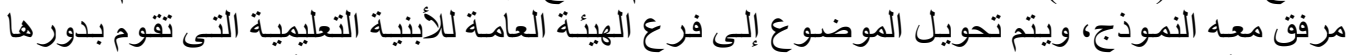

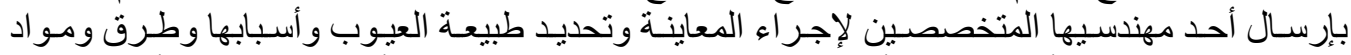

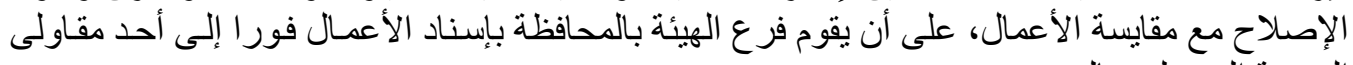

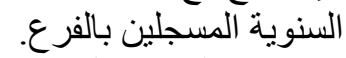

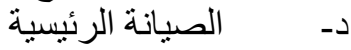

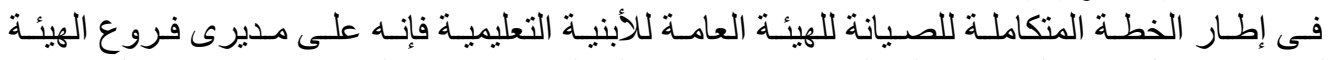

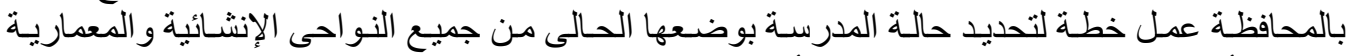

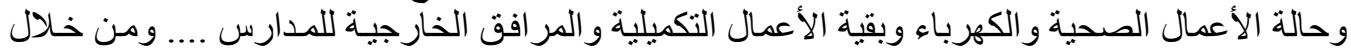

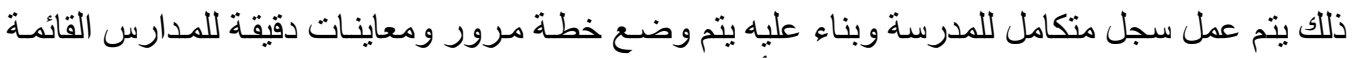

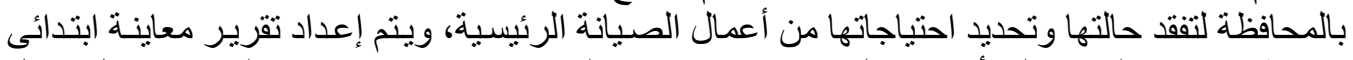

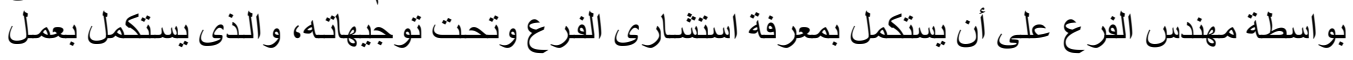

Journal of Engineering Sciences, Assiut University, Faculty of Engineering, Vol. 41, No. 2, pp. 617 -644, March, 2013,E-mail address: jes@aun.edu.eg 


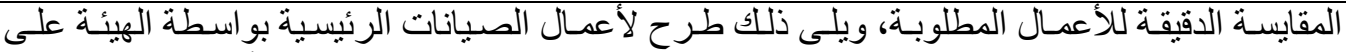

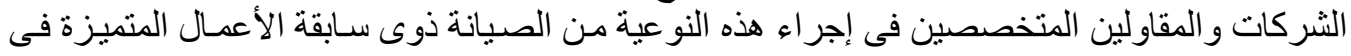
هذه المجالات. ويتم القيام بالصيانة الرئيسية للمدارس وفقا لأولويات الصيانة:

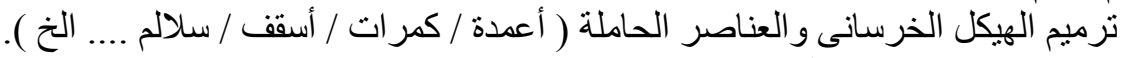
ترميم وصيانة دور ات الميكل التياه.

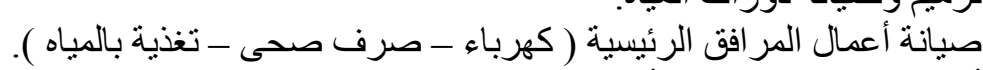

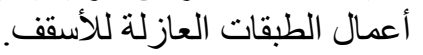

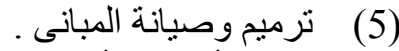

$$
\begin{aligned}
& \text { صيانة أعمال الأرضيات و التكسيات. } \\
& \text { إنشاء و استنكمال الأسوار الأريات } \\
& \text { صيانة أعمال البياض و الدهانات. } \\
& \text { خطوات الصبانة }
\end{aligned}
$$

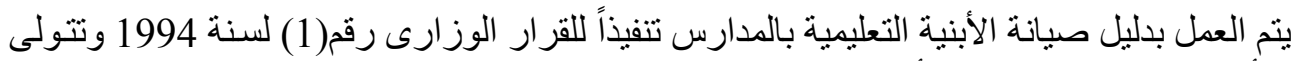

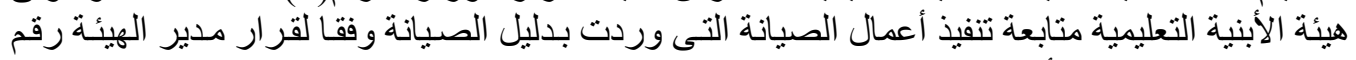

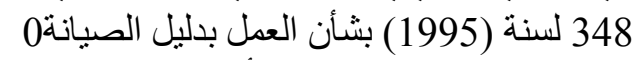

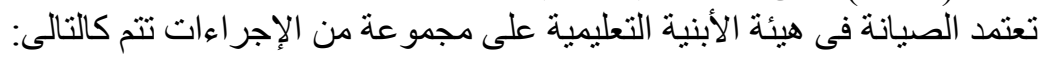

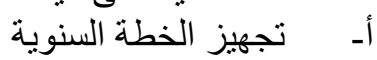

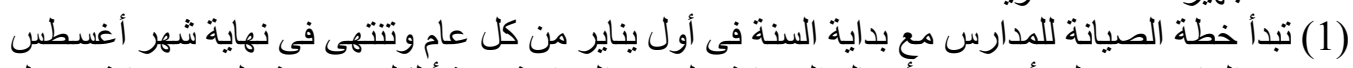

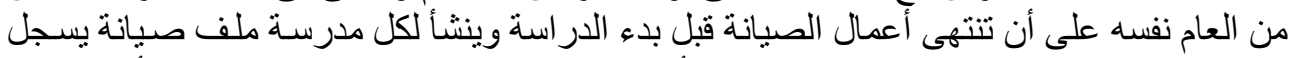

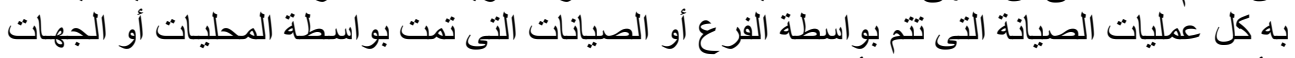

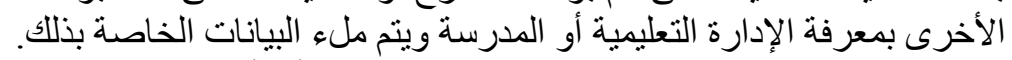

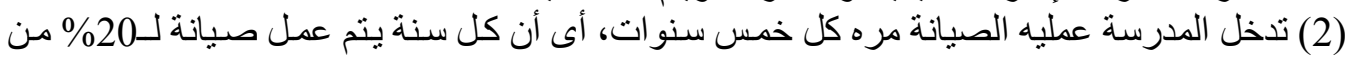

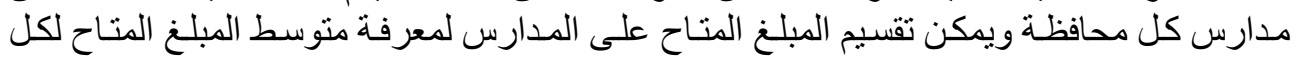

$$
\text { مدرسة. مدارس من مدير }
$$

(3) من حق مدير أى منطقة رفض ترميم أى مدرسة بها عيوب إنشائية مع كتابة تقرير بذلك.

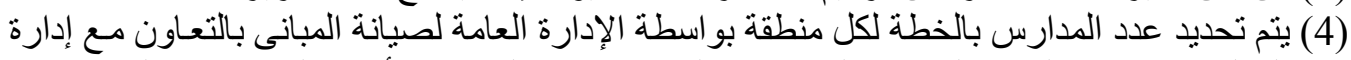

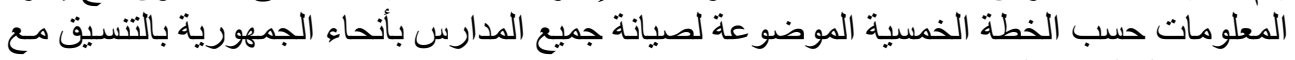
الإدار ات التعليمية بالمناطق.

(5) تقوم المنطقة بمعاينة هذه المدارس و اختيار العدد المحدد بالخطة طبقاً لأولويات أعمال الصيانة.

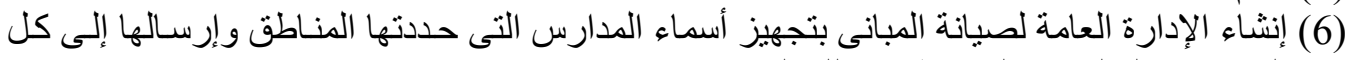

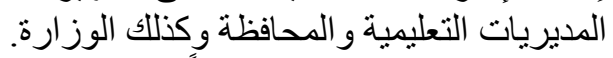

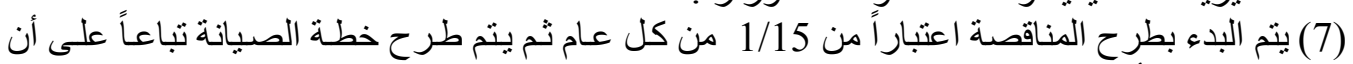

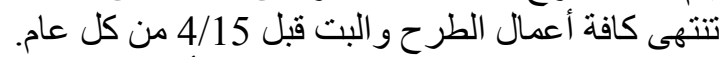

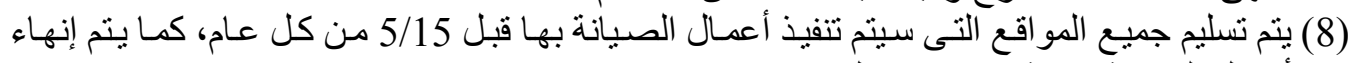
أعمال الصيانة بنهاية 8/15 هن كلع عام.

Journal of Engineering Sciences, Assiut University, Faculty of Engineering, Vol. 41, No. 2, pp. 617 -644, March,2013,E-mail address: jes@aun.edu.eg 
هشام عثمان عبد الرحن وآخرين - إجراءات صيانة مبانى التعليم "الدملكة الدتحدة وجمهورية مصر العربية

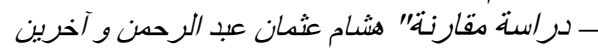

(9) ينت التنسيق مـع مديريات التربيـة و التعليم فئ شـأن نقل لجـان الامتحانـات مـن المدارس المخطط صيانتها.

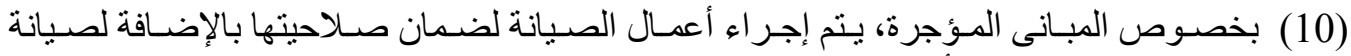

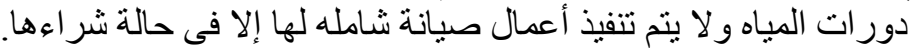

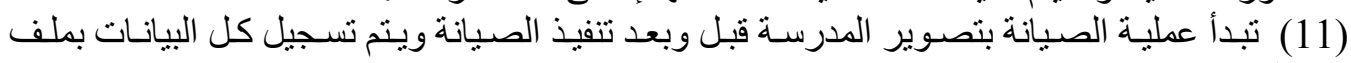
المدرسة.

(12) يتم إخطار إدار ات المتابعة وضبط الجودة بكل عمليات الصيانة بالمدارس.

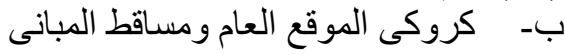

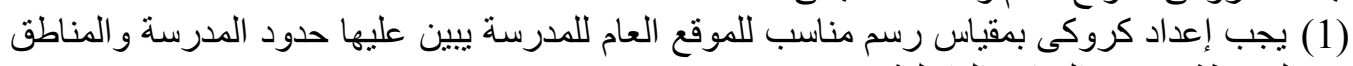
المحيطة وجميع المبانى الداخلية.

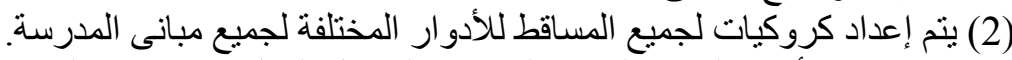

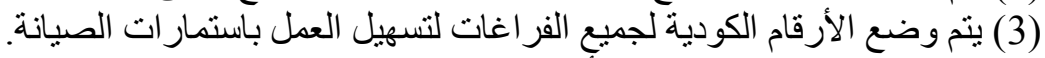

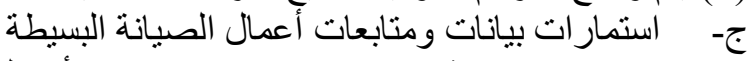

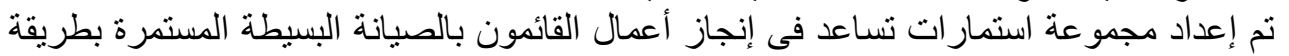

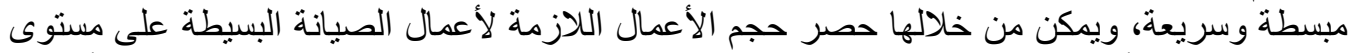

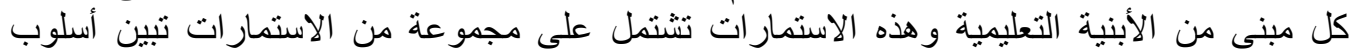

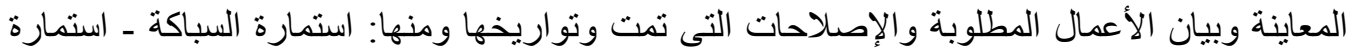
النجارة - استمارة الكهرباء ـ استمارة الدهانات ـ وكذا استمارة تلخص الألت الأعمال التى تمت على مدار السنة

د- استمار ات الصيانة العاجلة

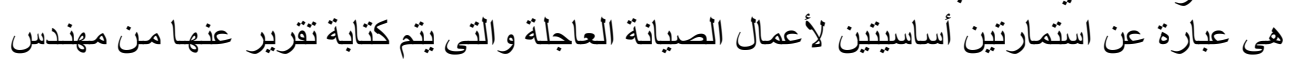

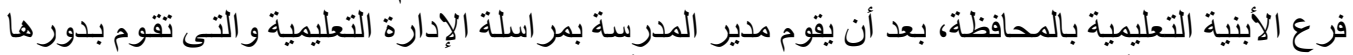

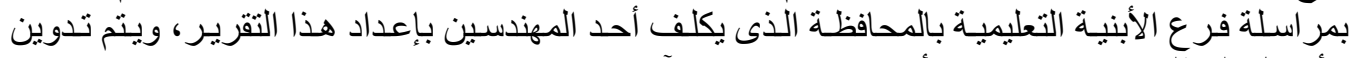
الأعمال المطلوبة من استمارتين أساسيتين بيانهما كالآتى:

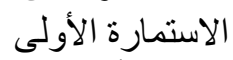

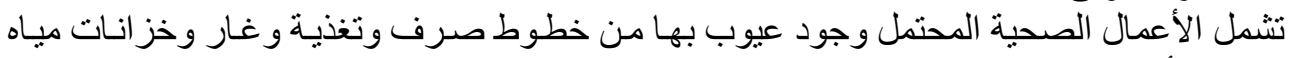

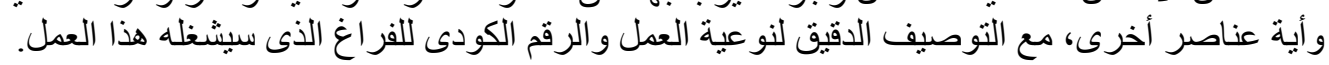

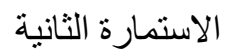

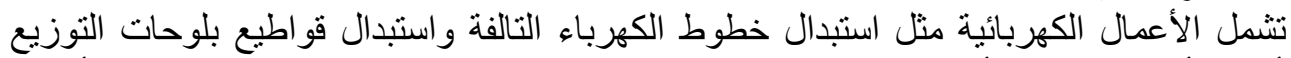

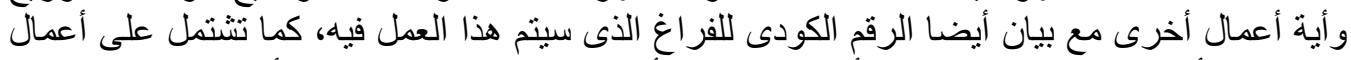

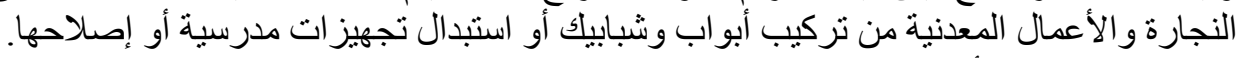

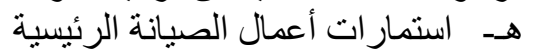

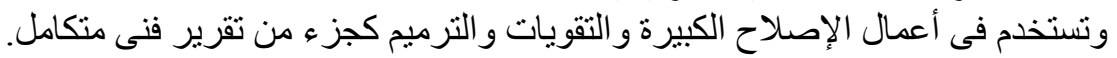

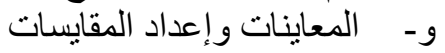

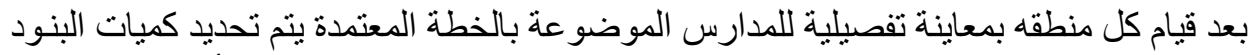

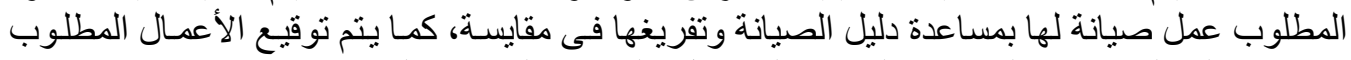

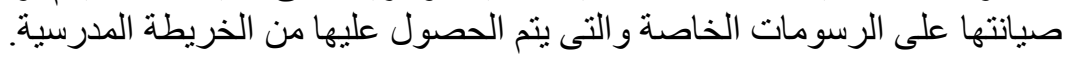

Journal of Engineering Sciences, Assiut University, Faculty of Engineering, Vol. 41, No. 2, pp. 617 -644, March, 2013,E-mail address: jes@aun.edu.eg 
هثام عثمان عبد الرحمن وآخرين - إجراءات صبانة مبانى التعليم "المدلكة المتحدة وجههورية مصر العربية

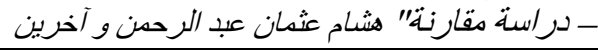

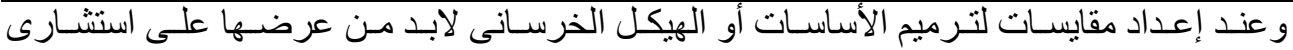

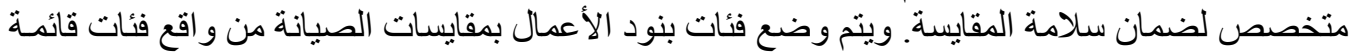

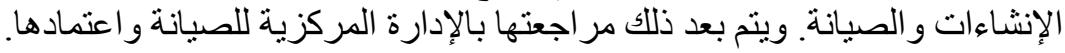

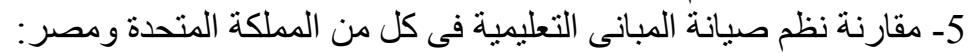

\begin{tabular}{|c|c|c|c|c|c|}
\hline \multirow[b]{2}{*}{ غير متوفر } & \multirow[b]{2}{*}{ 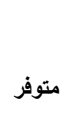 } & \multicolumn{2}{|c|}{ الملكة المتحدة } & \multirow[t]{2}{*}{ 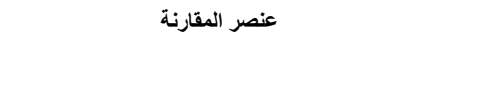 } & \multirow{2}{*}{ p } \\
\hline & & غير متوفر & متوفر & & \\
\hline \multirow[t]{2}{*}{$*$} & & & * & صبانة وقائية & 1 \\
\hline & * & * & & الاعتماد على الصبانة العلاجية & 2 \\
\hline \multirow[t]{3}{*}{ * } & & & * & 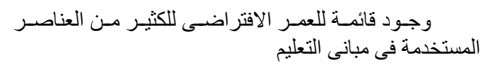 & 3 \\
\hline & $*$ & * & & وجود هيئة منفصلة للقيام بصيانة المبانى التعليمية. & 4 \\
\hline & $*$ & & $*$ & التعليمية للحكول المدات. & 5 \\
\hline$*$ & & & * & وأولياء الاممور جزء من نققات الصبانة على المجتمع الددرسى & 6 \\
\hline * & & & * & صياغة خطط صيانة سنوية للمبانى التعليمية قبل تنفيذها & 7 \\
\hline$*$ & & & * & خطط الصرانة. العمر الافتراضى ذات دور رئيسى فى صياغة & 8 \\
\hline * & & & * & بروز دور النقييم النهائى لخطط الصيانة & 9 \\
\hline \multirow[t]{2}{*}{ * } & & & * & على عمرها الاقتراضىى. & 10 \\
\hline & * & & * & دور الحكومة فى تمويل عمليات الصيانة. & 11 \\
\hline \multirow[t]{2}{*}{ * } & & & * & 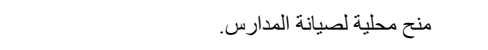 & 12 \\
\hline & * & * & & منح خارجية لصيانة الددارس & 13 \\
\hline * & & & * & تحديد المسئوليات والنقيد بالأدوار المختلفة لكل تخصص. & 14 \\
\hline
\end{tabular}

ومن خـلال الدارسـة البحثيـة السـابقة يمكن التوقف على سـلبيات التجربـة المصـرية في صـيانة المبـانى التعليميـة وهـى كالتالى:

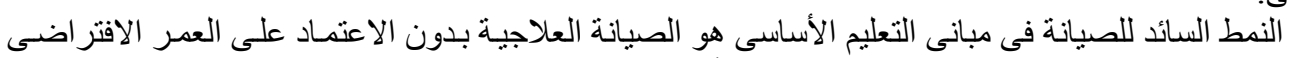

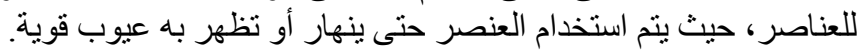

Journal of Engineering Sciences, Assiut University, Faculty of Engineering, Vol. 41, No. 2, pp. 617 -644, March, 2013,E-mail address: jes@aun.edu.eg 


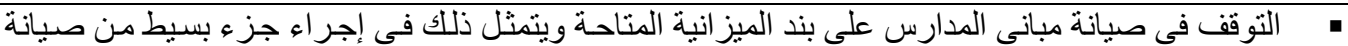

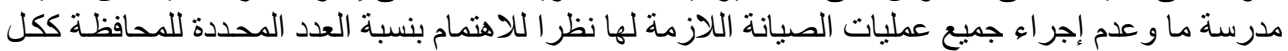
\%20)

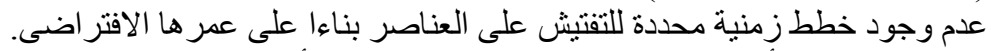

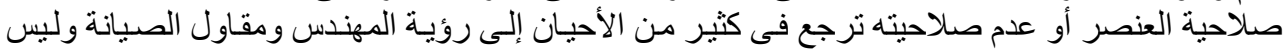

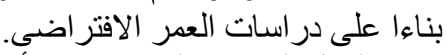

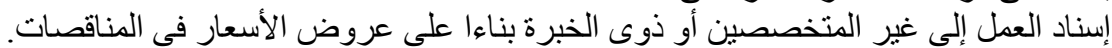

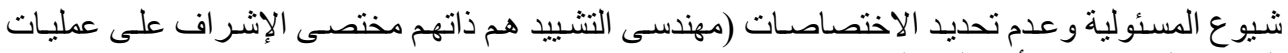
الصيانة التى يقوم بها أحد المقاولين).

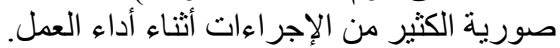

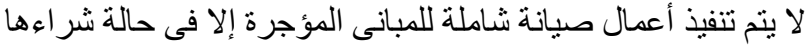

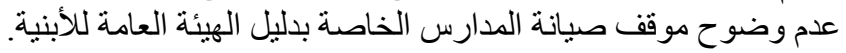

النتائج والتوصيات

1- نظام صبانة المبانى التعليمية فى أي دولة فى العالم ما هو إلا انعكاس للنظام القانوني والإدارى

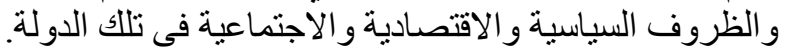

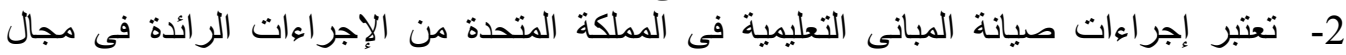
الصيانة الوقائية للمبانى التعليمية.

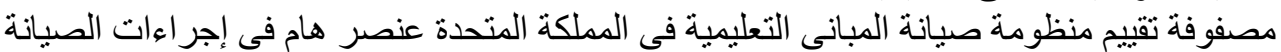
للمبانى التعليمية.

4- وجود قصور شديد فى إجر اءات و عمليات الصيانة للمبانى التعليمية بجمهورية مصر العربية.

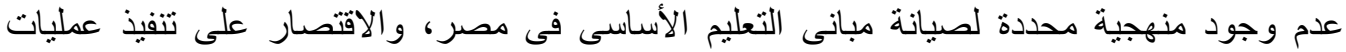

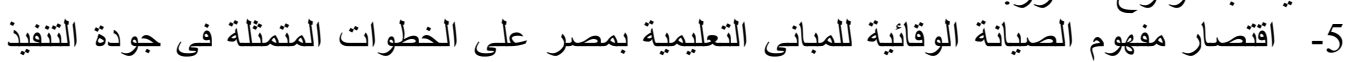

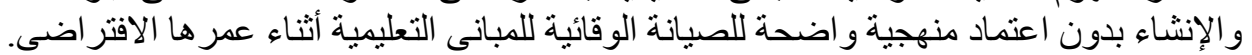

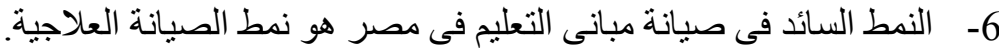

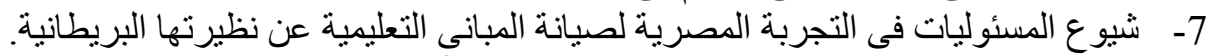

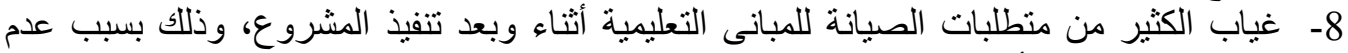

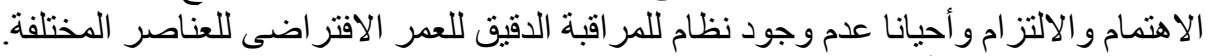

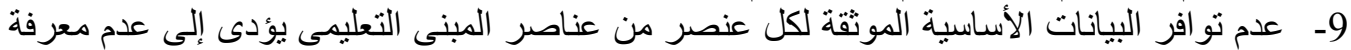
خصائصسه ولا كيفية صيانته فى مر احل عمر المبنى المختلفة الانسة

من النتائج السابقة يقترح البحث مجمو عة من التوصيات أهمها:

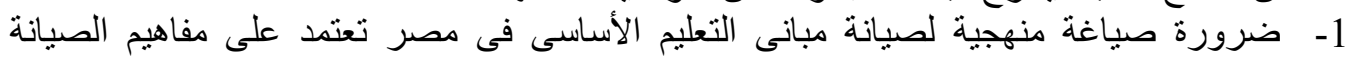
الوقائية وليست الصيانة العلاجية.

Journal of Engineering Sciences, Assiut University, Faculty of Engineering, Vol. 41, No. 2, pp. 617 -644, March,2013,E-mail address: jes@aun.edu.eg 
هشام عثمان عبد الرحمن وآخربن - إجراءات صيانة مبانى التعليم "المدلكة المتحدة وجدهورية مصر العربية

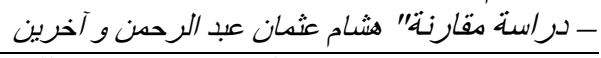

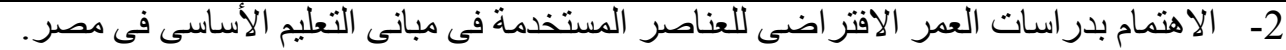

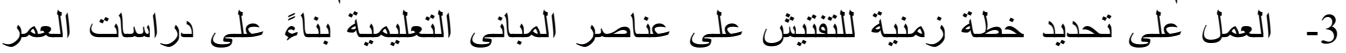

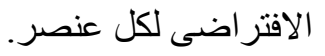

4- إعادة هيكلة كلا من قسم الصيانة وقسم التشييد بهيئة الأبنية التعليمية بمصر بما يتناسب مع الواقع الفعلى وبما يمنع من التداخل بين كن القسمين.

$$
\text { المراجع }
$$

[1] تـامر عـونى عبد القـادر،"إدارة وصيانة المبـانى الإدارية"،رسـالة ماجستير، كليـة الهندسـة، جامعـة عين شـس، 2007م.

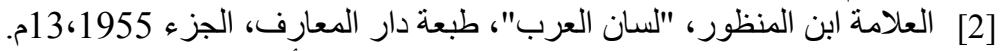

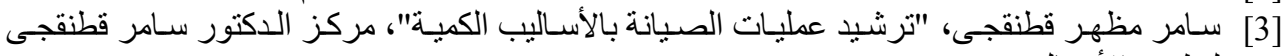

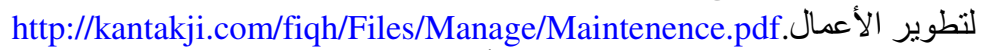

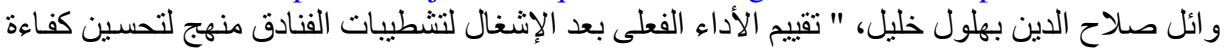

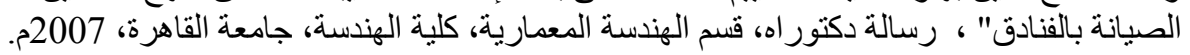

[5] Gilbert Architects Inc, "Howard County Public School System", April 2008. http://www.hcpss.org/schools/fac_03_glossary.pdf, [Accessed 4-10- 2010].

[6] Technology and Environmental Services,"DURABILITY GUIDELINES FOR BUILDING WALL ENVELOPES",Public Works \& Government Services Canada, 1997.

الإدارة العامة للبحوث و الدر اسات، "إستر اتيجية الصيانة وأساليب وبر امج التطبيق"، الهياتئة العامـة للأبنية

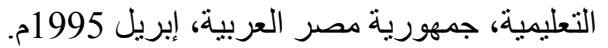
موقع العيئة العامة

http://www.gaeb.org/GAEBPortal/objective/allObjectives.jsp?key=4. للأبنيةالتعليمية

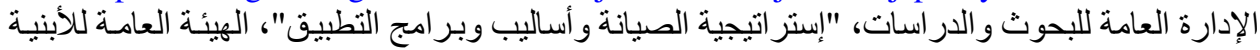

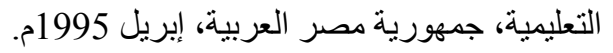

Journal of Engineering Sciences, Assiut University, Faculty of Engineering, Vol. 41, No. 2, pp. 617 -644, March,2013,E-mail address: jes@aun.edu.eg 


\title{
PROCEDURES FOR MAINTENANCE OF EDUCATIONAL BUILDINGS "THE KINGDOM AND THE UNITED ARAB REPUBLIC OF EGYPT - COMPARATIVE STUDY"
}

\author{
Hesham Osman Abd El Rahman ${ }^{1}$, Mohamed Abd-Elsamee Eid ${ }^{2}$ and Nady \\ Mostafa Abd-Elkarim 3,* \\ ${ }^{1}$ Tutor Department of Architecture, Faculty of Engineering, Al Azher University, Qena. \\ ${ }^{2}$ Professor of Architecture Faculty of Engineering, , \& Vice President of Assiut University. \\ ${ }^{3}$ Associate prof. in Architecture Department, Faculty of Engineering, Assiut University
}

(Received 22 July 2012; accepted 14 November 2012)

\begin{abstract}
Buildings and public facilities, especially in developing countries are considered national wealth which are necessary to preserve and maintain, not only for their cultural or functional value, but also they represent, wealth which is difficult to compensate with less financial resources and even non-existent in some cases. So their maintenance is important to maintain this wealth, extend the life of these buildings and develop them to be suitable for changing needs and requirements. Neglecting this maintenance leads to degradation, and may cause their demolition and removal to insure, the lives of their occupants in most cases when the treatment is difficult and impossible. Maintenance is considered as the third component after the basic design and implementation for any building. This maintenance is the conservative element of the building with the passage of time throughout its life.

The educational buildings are considered one of the buildings which represent a major national treasure so they must be maintained long periods of time in good condition to play its educational role in the most perfect and safest manner.

The research aims to highlight the procedures of maintaining educational buildings by reviewing and comparing between one of the most important systems of developed countries in the process of maintenance of buildings and the maintenance system of educational buildings in Egypt, through the review of legislation, administration and the stages of maintenance of educational buildings, and identifying similarities and differences in the performance of the two systems.

To achieve the objective of this research and through the analytical method, this search begins by giving a theoretical background of the main definitions and basic concepts for the maintenance of buildings, followed by studying the procedures of maintaining the educational buildings in both of the United Kingdom and Egypt, and finally extracting the most important positives and negatives through this study, in an attempt to give a clear view of measures to increase the effectiveness of the maintenance procedures of the educational buildings in Egypt. And finally the paper provides a number of results and recommendations to improve the procedures of maintaining the educational buildings.
\end{abstract}

Keywords: Maintenance - Educational buildings - United Kingdom - Egypt.

Journal of Engineering Sciences, Assiut University, Faculty of Engineering, Vol. 41, No. 2, pp. 617 -644, March,2013,E-mail address: jes@aun.edu.eg 